Article

\title{
Epidemiological Surveillance of Norovirus and Rotavirus in Sewage (2016-2017) in Valencia (Spain)
}

\author{
Cristina Santiso-Bellón ${ }^{1,+}+$, , Walter Randazzo ${ }^{1,2,+}$, Alba Pérez-Cataluña ${ }^{2}$, Susana Vila-Vicent ${ }^{1}$, \\ Roberto Gozalbo-Rovira ${ }^{1}\left(\mathbb{D}\right.$, Carlos Muñoz $^{1}$, Javier Buesa ${ }^{1}\left(\mathbb{D}\right.$, Gloria Sanchez $^{2}{ }^{\circledR}$ and \\ Jesús Rodríguez Díaz ${ }^{1, *(\mathbb{C})}$
}

1 Department of Microbiology, School of Medicine, University of Valencia, Av. Blasco Ibañez 17, 46010 Valencia, Spain; cristina.santiso@uv.es (C.S.-B.); walter.randazzo@uv.es (W.R.); susana.vila@uv.es (S.V.-V.); roberto.gozalbo@uv.es (R.G.-R.); carlos.munoz@uv.es (C.M.); javier.buesa@uv.es (J.B.)

2 Department of Preservation and Food Safety Technologies, IATA-CSIC, Av. Agustín Escardino 7, 46980 Paterna, Valencia, Spain; alba.perez@iata.csic.es (A.P.-C.); gloriasanchez@iata.csic.es (G.S.)

* Correspondence: jesus.rodriguez@uv.es; Tel.: +34-963864903; Fax: +34-963864960

+ These authors are equally contributed to this work.

Received: 25 November 2019; Accepted: 23 March 2020; Published: 24 March 2020

\begin{abstract}
The aim of the present study was to perform the molecular epidemiology of rotaviruses and noroviruses detected in sewage samples from a large wastewater facility from the city of Valencia, Spain. A total of 46 sewage samples were collected over a one-year period (September 2016 to September 2017). Norovirus and rotavirus were detected and quantified by RT-qPCR, genotyped by semi-nested RT-PCR and further characterized by sequencing and phylogenetic analyses. Noroviruses and rotaviruses were widely distributed in sewage samples (69.6\% for norovirus GI, 76.0\% norovirus GII, and $71.7 \%$ rotaviruses) and viral loads varied from 4.33 to $5.75 \log$ PCRU/L for norovirus GI, 4.69 to $6.95 \log$ PCRU/L for norovirus GII, and 4.08 to $6.92 \log$ PCRU/L for rotavirus. Overall, $87.5 \%(28 / 32)$ of GI noroviruses could not be genotyped, $6.25 \%$ (2/32) of the samples contained GI.2 genotype, and another $6.25 \%$ (2/32) were positive for GI.4 genotype. The most common genotype of GII noroviruses was GII.2 (40\%, 14/35), followed by GII.6 $(8.6 \%, 3 / 35)$ and GII.17 $(5.7 \%, 2 / 35)$ while the remaining GII strains could not be typed $(45.7 \%, 16 / 35)$. Rotavirus VP4 genotype P[8] was the only one found in 19 out of 33 rotavirus-positive samples (57.7\%). G2 was the most prevalent rotavirus VP7 genotype $(15.2 \%, 5 / 33)$ followed by G3, G9, and G12, with two positive samples for each genotype $(6.1 \%, 2 / 33)$. In one sample both G1 and G2 genotypes were detected simultaneously (3\%). The results presented here show that the surveillance of noroviruses and rotaviruses in sewage is useful for the study of their transmission in the population and their molecular epidemiology.
\end{abstract}

Keywords: rotavirus; norovirus; sewage; genotyping

\section{Introduction}

Diarrheal disease is the second cause of death in children under five years of age worldwide, producing around 525,000 deaths, with rotavirus and norovirus being responsible for the majority of the cases of non-bacterial acute gastroenteritis [1]. Norovirus is the leading cause of sporadic cases and outbreaks of acute gastroenteritis in children and adults [2,3], while rotavirus mainly causes disease in neonates and children under 5 years of age. Moreover, noroviruses show prolonged stability in environmental waters, resulting infectious in water for at least two months [4-6]. Worldwide, noroviruses are also the main cause of foodborne gastroenteritis outbreaks with an estimate of 120 million cases in 2010 [7]. The annual mortality associated with norovirus infections is of 200,000 deaths [8]. 
The genera Norovirus belongs to the Caliciviridae family and are further classified into ten distinct genogroups (GI-GX), that are subdivided into different genotypes [9]. Genogroups GI, GII, GIV, GVIII, and GXIX have been identified in infecting humans. Most of the human isolates belong to genogroups GI and GII that are further subdivided in 36 genotypes (GI.1-9, GII.1-28, and GII.15 has been withdrawn) [9]. The noroviruses are non-enveloped, icosahedral viruses with a single stranded, positive sense polyadenylated RNA genome [10]. The norovirus genome is organized into three open reading frames (ORFs), ORF2 encodes the major structural protein VP1 that forms the viral capsid with 180 copies structured in 90 dimers [11]. The VP1 protein can be divided in two regions, the shell (S) domain and the protruding $(\mathrm{P})$ domain [12].

Rotavirus belongs to the Reoviridae family and are divided into at least eight different groups or species, called A to H [13]. Rotavirus from the groups A, B, and C infect humans, and many animal species. The rotavirus from group $\mathrm{A}$ is the most important group infecting humans and can be further classified into G (depending on VP7, which is a glycoprotein) and P (from the VP4 protein, that is sensitive to proteases) types. So far, at least 36 G-genotypes and 51 P-genotypes have been identified among human and animal rotaviruses [14]. Viruses carrying G1P[8], G2P[4], G3P[8], and G4P[8] represent over $90 \%$ of human rotavirus strains co-circulating in most countries, although other $\mathrm{G}$ and P combinations like G9P[8] and G12P[8] are being isolated in increasing numbers [15].

Due to the public health relevance of rotavirus and norovirus infections it is necessary to implement rapid molecular techniques to perform an epidemiological surveillance of these viruses. In fact, sewage surveillance is a powerful approach to study the epidemiology and distribution of human enteric viruses in a population. This is because this type of water receives faeces and vomit with norovirus and rotavirus from symptomatic and asymptomatic individuals, many of whom do not go to the hospital, making it more difficult to carry out a good epidemiological surveillance. Enteric virus detection and characterization in sewage has been broadly used worldwide to study the molecular epidemiology of rotaviruses and noroviruses in given population areas from the beginning of the present century, in both high income and low income countries [16-21]. The efforts have been mainly focused on detecting, quantifying, and characterizing gastroenteritis-producing viruses such as rotavirus, norovirus, and adenovirus, but also hepatotropic viruses such as hepatitis $\mathrm{A}$ and hepatitis $\mathrm{E}$ viruses [22,23]. Polioviruses and other enteroviruses have also been detected and characterized from sewage samples [18] as well as emergent viruses like Aichi virus [24]. Thus, environmental virology is a powerful tool to study relevant human viruses in given areas. Here we present the first study of molecular epidemiology of rotavirus and norovirus from sewage samples from a large wastewater facility in the city of Valencia from September 2016 to September 2017.

\section{Materials and Methods}

\subsection{Sample Collection and Treatment}

Samples were collected weekly from the Quart-Benager municipal wastewater treatment plant of Xirivella (Valencia) from September 2016 to September 2017. This treatment plant receives wastewater from 6 municipalities (western Valencia) with about 164,000 habitants and has an average flow of $30,318 \mathrm{~m}^{3} /$ day.

Viral particles were concentrated by ultracentrifugation as previously done [18]. Briefly, $35 \mathrm{~mL}$ of sewage was centrifuged at $140,000 \times g$ for $2 \mathrm{~h} 30 \mathrm{~min}$ at $4{ }^{\circ} \mathrm{C}$ using a SW28 rotor. The elution of viral particles was achieved by adding $5 \mathrm{~mL}$ of $0.25 \mathrm{~N}$ glycine buffer ( $\mathrm{pH}$ 9.5) to the sediment and incubating on ice for $30 \mathrm{~min}$. The solution was neutralized by adding $5 \mathrm{~mL}$ of $2 \times$ phosphate-buffered saline. The suspended solids were removed by centrifugation $(12,000 \times g$ for $15 \mathrm{~min})$, and viruses were finally recovered by centrifugation at $229,600 \times g$ for $1 \mathrm{~h}$ at $4{ }^{\circ} \mathrm{C}$ in a $70 \mathrm{Ti}$ rotor. Viral particles were suspended in $500 \mu \mathrm{L}$ of $1 \times$ PBS. 


\subsection{RNA Extraction and Molecular Detection of Noroviruses and Rotaviruses}

Mengovirus (6 log PCRU/L, CECT 100000) was added to $35 \mathrm{~mL}$ of sewage as process control virus to monitor extraction efficiency following the ISO 15216:2017 guidelines. Viral RNA was extracted from $125 \mu \mathrm{L}$ of sample concentrates with the NucleoSpin ${ }^{\circledR}$ RNA Virus Kit (Macherey-Nagel, Düren, Germany), following the manufacturer's instructions and including the Plant RNA Isolation Aid (Ambion, Austin, TX, USA) pre-treatment to remove potential PCR inhibitors such as polyphenolics and polysaccharides $[25,26]$. Then, RNA was finally eluted in $50 \mu \mathrm{L}$ of RNase-free $\mathrm{H}_{2} \mathrm{O}$. Mengovirus, rotavirus, norovirus GI, and GII amplification of direct and ten-folded diluted RNA samples was performed using one-step TaqMan RT-qPCR with the RNA UltraSense One-Step quantitative system (Invitrogen SA, Carlsbad, CA, USA) in the LightCycler 480 instrument (Roche Diagnostics, Risch-Rotkreuz, Switzerland). Each $10 \mu \mathrm{L}$ reaction mix contained $2 \mu \mathrm{L}$ of $2 \times$ master mix and $2.5 \mu \mathrm{L}$ of RNA. Norovirus GI, GII, and mengovirus reaction mixes contained TaqMan ${ }^{\circledR}$ probe at a final concentration of $250 \mathrm{nM}$, a reverse primer at $900 \mathrm{nM}$, and forward primer at $500 \mathrm{nM}$. For rotavirus, the TaqMan ${ }^{\circledR}$ probe was used at a final concentration of $100 \mathrm{nM}$, and the primers were used at a final concentration of $250 \mathrm{nM}$ (each). The set of primers and probes used for norovirus [27,28], rotavirus [29], and mengovirus $[28,30]$ are reported in Table 1.

For mengovirus and norovirus GI and GII, RT-qPCR amplification was performed for 1 cycle at $55^{\circ} \mathrm{C}$ for $1 \mathrm{~h}, 1$ cycle at $95^{\circ} \mathrm{C}$ for $5 \mathrm{~min}$, and 45 cycles of $95^{\circ} \mathrm{C}$ for $15 \mathrm{~s}, 60^{\circ} \mathrm{C}$ for $1 \mathrm{~min}$ and $65^{\circ} \mathrm{C}$ for $1 \mathrm{~min}$ [28]. For rotavirus, RT-qPCR amplifications were performed using the following conditions: Reverse transcriptase reaction for $30 \mathrm{~min}$ at $50{ }^{\circ} \mathrm{C}$, followed by denaturation at $95^{\circ} \mathrm{C}$ for $15 \mathrm{~min}$, followed by 45 cycles of denaturation at $94{ }^{\circ} \mathrm{C}$ for $10 \mathrm{~s}$, annealing at $55^{\circ} \mathrm{C}$ for $30 \mathrm{~s}$ (fluorescence data collection at the end of annealing step), and extension at $72{ }^{\circ} \mathrm{C}$ for $20 \mathrm{~s}$.

Standard curves for mengovirus, rotavirus, norovirus GI, and GII were generated by amplifying 10-fold dilutions of viral suspensions by RT-qPCR in quintuplicates.

Specifically, stool samples containing norovirus GI genotype 4 (GI.4) and GII genotype 4 (GII.4 variant Den Haag 2006b) were used to generate the standard curve. Stool samples were suspended $(10 \%, \mathrm{wt} / v)$ in phosphate-buffered saline (PBS) containing $2 \mathrm{M}$ NaNO3 (Panreac, Barcelona, Spain), $1 \%$ beef extract (Condalab, Madrid, Spain), and 0.1\% Triton X-100 (Fisher Scientific, Madrid, Spain) (pH 7.2), vortexed and centrifuged at $1000 \times g$ for $5 \mathrm{~min}$. The supernatant was subsequently processed using the NucleoSpin ${ }^{\circledR}$ RNA virus kit according to the manufacturer's instructions.

Similarly, the standard curve for rotavirus was generated by serial end-point dilution, amplifying 10-fold dilutions of a quantified stock of Wa rotavirus strain (ATCC VR-2018) by RT-qPCR in quintuplicates. For each virus, the crossing points (Cp) obtained from the assay of each dilution were used to plot a standard curve by assigning a value of 1 RT-PCR unit (PCRU) to the highest dilution showing a positive $\mathrm{Cp}$ value and progressively 10-fold-higher values to the lower dilutions [31,32]. 
Table 1. Sequences of primers and probes utilized in the present study. The asterisk $\left(^{*}\right)$ indicate the names of the primers used for sequencing.

\begin{tabular}{|c|c|c|c|c|}
\hline Target & Purpose & Primer or Probe Name & Sequence & Nucleotide Positions \\
\hline Norovirus GI & qPCR & QNIF4 & 5'-CGC TGG ATG CGN TTC CAT-3' & $5291-5308$ \\
\hline Norovirus GI & qPCR & NV1LCR & 5'-CCT TAG ACG CCA TCA TCA TTT AC-3' & $5354-5376$ \\
\hline Norovirus GI & qPCR & NVGG1p & VIC-5'-TGG ACA GGA GAY CGC RAT CT-3'-Quencher & $5321-5340$ \\
\hline Norovirus GII & qPCR & QNIF2 & 5'-ATG TTC AGR TGG ATG AGR TTC TCW GA-3' & $5012-5037$ \\
\hline Norovirus GII & qPCR & COG2R & 5'-TCG ACG CCA TCT TCA TTC ACA-3' & $5080-5100$ \\
\hline Norovirus GII & qPCR & QNIFs & FAM-5'-AGC ACG TGG GAG GGC GAT CG-3'-Quencher & $5042-5061$ \\
\hline Mengovirus & qPCR & Mengo 110 & 5'-GCG GGT CCT GCC GAA AGT-3' & $110-127$ \\
\hline Mengovirus & qPCR & Mengo 209 & 5'-GAA GTA ACA TAT AGA CAG ACG CAC AC-3' & $245-270$ \\
\hline Mengovirus & qPCR & Mengo 147 & FAM-5'-ATC ACA TTA CTG GCC GAA GC-3'-Quencher & $209-227$ \\
\hline Norovirus GI & 1st PCR & COG1F & 5'-CGY TGG ATG CGN TTY CAT GA-3' & $5291-5311$ \\
\hline Norovirus GI & 1st PCR/2nd PCR & ${ }^{*}$ G1SKR & 5'-CCA ACC CAR CCA TTR TAC A-3' & $5653-5671$ \\
\hline Norovirus GI & 2nd PCR & ${ }^{*}$ G1SKF & 5'-CTG CCC GAA TTY GTA AAT GA-3' & $5342-5361$ \\
\hline Norovirus GII & 1st PCR & COG2F & 5'-CAR GAR BCN ATG TTY AGR TGG ATG AG-3' & $5003-5029$ \\
\hline Norovirus GII & 1st PCR/2nd PCR & ${ }^{*}$ G2SKR & 5'-CCR CCN GCA TRH CCR TTR TAC AT-3' & $5379-5401$ \\
\hline Norovirus GII & 2nd PCR & ${ }^{*} \mathrm{G} 2 \mathrm{SKF}$ & $5^{\prime}$-CNT GGG AGG GCG ATC GCA A-3' & 5058-5076 \\
\hline Rotavirus NSP3 & qPCR & JVKF & 5'-CAG TGG TTG ATG CTC AAG ATG GA-3' & $17-39$ \\
\hline Rotavirus NSP3 & qPCR & JVKR & 5'-TCA TTG TAA TCA TAT TGA ATA CCC A-3' & $123-147$ \\
\hline Rotavirus NSP3 & qPCR & JVKP & FAM-5'-ACA ACT GCA GCT TCA AAA GAA GWG T-3-Quencher & $72-96$ \\
\hline Rotavirus VP7 & 1st PCR & VP7-F & $5^{\prime}$-ATG TAT GGT ATT GAA TAT ACC AC-3' & $51-71$ \\
\hline Rotavirus VP7 & 1st PCR/2nd PCR & *VP7-R & 5'-AAC TTG CCA CCA TTT TTT CC-3' & 914-932 \\
\hline Rotavirus VP7 & 2nd PCR & ${ }^{*} \mathrm{G} 1$ & 5'-CAA GTA CTC AAA TCA ATG ATG G-3' & $314-335$ \\
\hline Rotavirus VP7 & 2nd PCR & ${ }^{*} \mathrm{G} 2$ & 5'-CAA TGA TAT TAA CAC ATT TTC TGT G-3' & $411-435$ \\
\hline Rotavirus VP7 & 2nd PCR & ${ }^{*} \mathrm{G} 3$ & 5'-ACG AAC TCA ACA CGA GAG G-3' & $250-269$ \\
\hline Rotavirus VP7 & 2nd PCR & G4 & 5'-CGT TTC TGG TGA GGA GTT G-3' & $480-499$ \\
\hline Rotavirus VP7 & 2nd PCR & G8 & 5'-GTC ACA CCA TTT GTA AAT TCG-3' & 178-198 \\
\hline
\end{tabular}


Table 1. Cont.

\begin{tabular}{|c|c|c|c|c|}
\hline Target & Purpose & Primer or Probe Name & Sequence & Nucleotide Positions \\
\hline Rotavirus VP7 & 2nd PCR & ${ }^{*} \mathrm{G} 9$ & 5'-CTT GAT GTG ACT AYA AAT AC-3' & $757-776$ \\
\hline Rotavirus VP7 & 2nd PCR & G10 & 5'-ATG TCA GAC TAC ARA TAC TGG-3' & $666-687$ \\
\hline Rotavirus VP7 & 2nd PCR & ${ }^{*} \mathrm{G} 12$ & 5'-GGT TAT GTA ATC CGA TGG ACG-3' & $548-567$ \\
\hline Rotavirus VP4 & 1st PCR/2nd PCR & ${ }^{*}$ VP4-F & 5'-TAT GCT CCA GTN AAT TGG-3' & $132-149$ \\
\hline Rotavirus VP4 & 1st PCR & VP4-R & 5'-ATT GCA TTT CTT TCC ATA ATG-3' & $775-795$ \\
\hline Rotavirus VP4 & 2nd PCR & $\mathrm{P}[4]-\mathrm{R}$ & 5'-CTA TTG TTA GAG GTT AGA GTC-3' & $474-494$ \\
\hline Rotavirus VP4 & 2nd PCR & $\mathrm{P}[6]-\mathrm{R}$ & 5'-TGT TGA TTA GTT GGA TTC AA-3' & $259-278$ \\
\hline Rotavirus VP4 & 2nd PCR & ${ }^{*} \mathrm{P}[8]-\mathrm{R}$ & 5'-TCT ACT GGR TTR CAN TGC-3' & $339-356$ \\
\hline Rotavirus VP4 & 2nd PCR & $\mathrm{P}[9]-\mathrm{R}$ & 5'-TGA GAC ATG CAA TTG GAC-3' & $385-402$ \\
\hline Rotavirus VP4 & 2nd PCR & $P[10]-R$ & 5'ATC ATA GTT AGT AGT CGG-3' & $575-594$ \\
\hline Rotavirus VP4 & 2nd PCR & $P[11]-R$ & 5'-GTA AAC ATC CAG AAT GTG-3' & $305-323$ \\
\hline
\end{tabular}




\subsection{Sequencing and Phylogenetic Analysis}

For the reverse transcription, $1 \mu \mathrm{L}$ of $50 \mu \mathrm{M}$ random primer (Biotools, Madrid, Spain) was added to $9 \mu \mathrm{L}$ of each RNA sample denatured at $65^{\circ} \mathrm{C}$ for $5 \mathrm{~min}$. Each sample (RNA and random primer) contained a mixture of $1 \times$ Buffer (Invitrogen), $5 \mathrm{mM}$ DTT (Invitrogen), $0.3 \mathrm{mM}$ dNTPs (Biotools), $0.3 \mathrm{U}$ RNasin (Biotools), and $0.2 \mu \mathrm{L}$ of $1.3 \mathrm{U}$ SuperScript ${ }^{\circledR}$ III with a final reaction volume of $30 \mu \mathrm{L}$ [33]. Then, each mixture was heated to $50^{\circ} \mathrm{C}$ for $50 \mathrm{~min}$ for RT, followed by $70{ }^{\circ} \mathrm{C}$ for $15 \mathrm{~min}$. Semi-nested RT-PCR assays were performed by standardized methods [33] in order to determine the G and P types of rotavirus. Briefly, the RNA extracted was reverse transcribed and amplified using consensus primer pairs VP7-F/VP7-R and VP4-F/VP4-R (Table 1), encoding the VP7 and VP4 genes as described previously. This was followed by semi-nested PCR using the specific primers that identify the most relevant $G$ and $P$ types [34] (Table 1). Genogroup I and II of norovirus were determined through semi-nested PCR using the primers COG1F-G1SKR and COG2F-G2SKR in a first round, respectively. The second round was done with the primers G1SKF-G1SKR and G2SKF-G2SKR, respectively $[35,36]$ (Table 1).

The PCRs were performed as follow, $2.5 \mu \mathrm{L}$ of cDNA were amplified in $1 \times$ Buffer with $2 \mathrm{mM}$ $\mathrm{MgCl}_{2}$ (Biotools), $0.3 \mathrm{mM}$ dNTPs (Biotools), $0.6 \mu \mathrm{M}$ of each primer, and $1 \mathrm{U}$ DNA polymerase (Biotools) in a final volume of $25 \mu \mathrm{L}$. Then, each mixture was subjected to $94^{\circ} \mathrm{C}$ for $2 \mathrm{~min}$ followed by 35 cycles of $94{ }^{\circ} \mathrm{C}$ for $30 \mathrm{~s}, 50^{\circ} \mathrm{C}$ for $30 \mathrm{~s}$, and $72{ }^{\circ} \mathrm{C}$ for $30 \mathrm{~s}$. The final extension step was carried out at $72{ }^{\circ} \mathrm{C}$ for $10 \mathrm{~min}$. PCR products were analyzed by gel electrophoresis on $2 \%$ agarose gels.

PCR products obtained from the second round of amplification were purified with GeneJET Gel Extraction or the GeneJET PCR Purification kit (Thermo Scientific) and sequenced in both directions. Sequencing was done by Sanger sequencing services from GATC Biotech. The quality of sequences was checked and manually corrected with BioEdit software v7.0.0 [37]. All sequences were deposited to GenBank accession number from MN621364 to MN621395 (rotavirus), MN602934 to MN602937 (norovirus GI), and from MN602951 to MN602969 (norovirus GII).

Phylogenetic trees were built with the sewage sequences and reference sequences obtained from Genbank. Sequences were aligned with the Clustal X 2.0 method [38] and matched with Genedoc 2.7.000 [39]. Finally, phylogenetic analyses were conducted using MEGA7 (Molecular Evolutionary Genetics Analysis v7.0 for bigger datasets) [40]. Models with the lowest BIC scores (Bayesian Information Criterion) are considered to describe the substitution pattern. In addition, the best model suggested by the program was used to calculate the degree of nucleotide sequence identity between the sequences studied. The evolutionary history was inferred by the Maximum Likelihood method [41] using a bootstrap test of 1000 replicates to assess tree reliability.

\section{Results}

\subsection{Prevalence of Rotaviruses and Noroviruses in Sewage Samples from Valencia}

In the present study a total of 46 sewage samples collected from September 2016 to September 2017 were analyzed. Table 2 summarizes the results including the data for norovirus GI, norovirus GII, and rotavirus. The recovery of spiked mengovirus was determined (Table 1) and ranged from $1.18 \%$ to $26.30 \%$, complying with the recovery efficiency indicated in the ISO 15216-1:2017 to validate viral concentration in bottled water and food matrices ( $>1 \%$ of mengovirus recovery). 
Table 2. Prevalence, viral loads ( $\log _{10}$ PCRU/L) and genotypes of norovirus GI, norovirus GII, and rotavirus.

\begin{tabular}{|c|c|c|c|c|c|c|c|c|c|}
\hline \multirow{3}{*}{ Sample } & \multirow{3}{*}{ Sample } & \multirow{3}{*}{ Sampling Date } & \multicolumn{4}{|c|}{ Norovirus } & \multirow{2}{*}{\multicolumn{2}{|c|}{ Rotavirus }} & \multirow{3}{*}{$\begin{array}{c}\text { Recovery } \\
\text { Efficiency }\end{array}$} \\
\hline & & & \multicolumn{2}{|c|}{ GI Norovirus } & \multicolumn{2}{|c|}{ GII Norovirus } & & & \\
\hline & & & Genotype & $\log \mathrm{PCRU} / \mathrm{L} \pm \mathrm{SD}$ & Genotype & $\log \mathrm{PCRU} / \mathrm{L} \pm \mathrm{SD}$ & Genotype & $\log \mathrm{PCRU} / \mathrm{L} \pm \mathrm{SD}$ & \\
\hline R1 & $\# 1$ & 29.9 .16 & ND & $4.98 \pm 0.43$ & ND & $6.13 \pm 0.05$ & GxP[8] & $5.21 \pm 0.08$ & 1.47 \\
\hline R3 & $\# 2$ & 18.10 .16 & GI.4 & $4.74 \pm 0.32$ & GII.2 & $6.12 \pm 0.35$ & GxP[8] & $5.46 \pm 0.14$ & 5.11 \\
\hline $\mathrm{R} 4$ & $\# 3$ & 20.10 .16 & ND & $5.01 \pm 0.25$ & GII.2 & $6.60 \pm 0.01$ & GxP[8] & $4.62 \pm 0.18$ & 2.22 \\
\hline R5 & $\# 4$ & 27.10 .16 & ND & $4.92 \pm 0.06$ & GII.2 & $6.13 \pm 0.12$ & G12P[8] & $4.14 \pm 0.10$ & 4.37 \\
\hline R9 & $\# 5$ & 17.11 .2016 & ND & $4.66 \pm 0.64$ & GII.2 & $6.39 \pm 0.00$ & G2P[8] & $5.03 \pm 0.06$ & 7.73 \\
\hline R10 & $\# 6$ & 24.11 .2016 & ND & $5.04 \pm 0.28$ & GII.2 & $6.46 \pm 0.11$ & ND & $5.77 \pm 0.22$ & 6.39 \\
\hline R11 & $\# 7$ & 2.12 .2016 & ND & $4.89 \pm 0.06$ & GII.2 & $6.24 \pm 0.15$ & G9P[8] & 5.26 & 1.37 \\
\hline $\mathrm{R} 12 \mathrm{~A}$ & $\# 8$ & 6.12 .2016 & ND & $5.47 \pm 0.43$ & GII.2 & $6.95 \pm 0.10$ & G2P[8] & $<\mathrm{LOD}$ & 7.62 \\
\hline R13 & $\# 9$ & 21.12 .2016 & ND & $5.09 \pm 0.13$ & GII.2 & $6.02 \pm 0.00$ & G3P $[x]$ & 5.97 & 6.73 \\
\hline R14 & $\# 10$ & 30.12 .2016 & ND & $5.36 \pm 0.19$ & GII.2 & $6.95 \pm 0.05$ & GxP[8] & $6.20 \pm 0.12$ & 7.38 \\
\hline R51 & $\# 11$ & 15.12 .2016 & ND & $5.19 \pm 0.32$ & $\mathrm{ND}$ & $6.22 \pm 0.13$ & $\mathrm{G} 2 \mathrm{P}[\mathrm{x}]$ & $<$ LOD & 8.54 \\
\hline R15 & $\# 12$ & 4.01 .2017 & ND & $5.62 \pm 0.19$ & GII.2 & $6.44 \pm 0.10$ & G12P[8] & $<$ LOQ & 7.73 \\
\hline R17 & $\# 14$ & 18.01.2017 & ND & $<\mathrm{LOD}$ & ND & $6.54 \pm 0.18$ & ND & $<$ LOD & 8.38 \\
\hline R18 & $\# 15$ & 15.02.2017 & ND & $<\mathrm{LOD}$ & ND & $<\mathrm{LOD}$ & GxP[8] & $6.24 \pm 0.05$ & 3.68 \\
\hline R19 & $\# 16$ & 16.02 .2017 & ND & $4.70 \pm 0.21$ & GII.2 & $6.14 \pm 0.09$ & G9P $[x]$ & $5.34 \pm 0.04$ & 4.79 \\
\hline R20 & $\# 17$ & 2.02.2017 & ND & $5.55 \pm 0.04$ & GII.2 & $6.53 \pm 0.34$ & GxP[8] & $5.05 \pm 0.09$ & 10.82 \\
\hline R21 & $\# 18$ & 22.02 .2017 & ND & $5.47 \pm 0.08$ & GII.2 & $6.19 \pm 0.76$ & $\mathrm{ND}$ & $4.08 \pm 0.23$ & 4.39 \\
\hline $\mathrm{R} 22$ & $\# 19$ & 02.03.2017 & ND & $<\mathrm{LOD}$ & GII.6 & $5.38 \pm 0.21$ & GxP[8] & $6.32 \pm 0.81$ & 18.39 \\
\hline $\mathrm{R} 23$ & $\# 20$ & 08.03.2017 & GI.2 & $<\mathrm{LOD}$ & ND & 6.25 & $\mathrm{ND}$ & $<\mathrm{LOD}$ & 20.50 \\
\hline R24 & $\# 21$ & 15.03 .2017 & GI.2 & $5.62 \pm 0.05$ & ND & $5.01 \pm 1.71$ & GxP[8] & $6.55 \pm 0.25$ & 12.50 \\
\hline R25 & $\# 22$ & 23.03 .2017 & ND & $4.80 \pm 0.02$ & ND & $5.82 \pm 0.05$ & GxP[8] & $6.85 \pm 0.22$ & 11.39 \\
\hline $\mathrm{R} 26$ & $\# 23$ & 30.03 .2017 & ND & $<\mathrm{LOD}$ & ND & $<\mathrm{LOD}$ & ND & $6.19 \pm 0.08$ & 1.18 \\
\hline
\end{tabular}


Table 2. Cont.

\begin{tabular}{|c|c|c|c|c|c|c|c|c|c|}
\hline \multirow{3}{*}{ Sample } & \multirow{3}{*}{ Sample } & \multirow{3}{*}{ Sampling Date } & \multicolumn{4}{|c|}{ Norovirus } & \multirow{2}{*}{\multicolumn{2}{|c|}{ Rotavirus }} & \multirow{3}{*}{$\begin{array}{c}\text { Recovery } \\
\text { Efficiency } \\
\%\end{array}$} \\
\hline & & & \multicolumn{2}{|c|}{ GI Norovirus } & \multicolumn{2}{|c|}{ GII Norovirus } & & & \\
\hline & & & Genotype & $\log \mathrm{PCRU} / \mathrm{L} \pm \mathrm{SD}$ & Genotype & $\log \mathrm{PCRU} / \mathrm{L} \pm \mathrm{SD}$ & Genotype & $\log \mathrm{PCRU} / \mathrm{L} \pm \mathrm{SD}$ & \\
\hline R27 & $\# 24$ & 06.04 .2017 & ND & $<\mathrm{LOD}$ & ND & $<\mathrm{LOD}$ & ND & $<\mathrm{LOD}$ & 1.97 \\
\hline R28 & $\# 25$ & 12.04 .2017 & ND & $4.87 \pm 0.10$ & ND & $5.34 \pm 0.00$ & ND & $6.92 \pm 0.04$ & 2.82 \\
\hline R29 & $\# 26$ & 27.04 .2017 & ND & $<$ LOD & ND & $<$ LOD & G2P[8] & 4.59 & 4.31 \\
\hline R30 & $\# 27$ & 04.05 .2017 & ND & $<\mathrm{LOD}$ & ND & $<\mathrm{LOD}$ & ND & $6.31 \pm 0.04$ & 4.75 \\
\hline R31 & $\# 28$ & 11.05 .2017 & ND & $<\mathrm{LOD}$ & ND & $<\mathrm{LOD}$ & G3P[8] & $<\mathrm{LOD}$ & 11.03 \\
\hline R32 & $\# 29$ & 18.05 .2017 & ND & $<\mathrm{LOD}$ & GII.6 & $<\mathrm{LOD}$ & GxP[8] & $6.13 \pm 0.01$ & 9.05 \\
\hline R33 & $\# 30$ & 25.02 .2017 & ND & $<\mathrm{LOD}$ & ND & $<\mathrm{LOD}$ & GxP[8] & 6.80 & 9.34 \\
\hline R34 & $\# 31$ & 01.06 .2017 & ND & $<\mathrm{LOD}$ & ND & 5.17 & ND & $<\mathrm{LOD}$ & 6.73 \\
\hline R35 & $\# 32$ & 08.06 .2017 & ND & $<\mathrm{LOD}$ & ND & $<\mathrm{LOD}$ & ND & 4.99 & 2.02 \\
\hline R36 & $\# 33$ & 15.06 .2017 & ND & $4.33 \pm 0.45$ & ND & $<\mathrm{LOD}$ & ND & 5.28 & 7.10 \\
\hline R37 & $\# 34$ & 22.06 .2017 & ND & $4.81 \pm 0.57$ & ND & $4.69 \pm 0.00$ & ND & $<$ LOD & 9.40 \\
\hline R38 & $\# 35$ & 28.06.2017 & ND & $5.41 \pm 0.01$ & GII.17 & $5.04 \pm 0.27$ & ND & 5.98 & 2.48 \\
\hline R40 & $\# 37$ & 06.07.2017 & ND & $5.03 \pm 0.02$ & GII.17 & $<\mathrm{LOD}$ & ND & 4.95 & 3.53 \\
\hline R41 & $\# 38$ & 13.07.2017 & GI.4 & $5.73 \pm 0.54$ & ND & $5.50 \pm 0.15$ & ND & $<\mathrm{LOD}$ & 8.04 \\
\hline R42 & $\# 39$ & 20.07.2017 & ND & $5.75 \pm 0.31$ & ND & $5.25 \pm 0.00$ & ND & $4.73 \pm 0.10$ & 2.34 \\
\hline R43 & $\# 40$ & 27.07.2017 & ND & $5.49 \pm 0.22$ & ND & $5.58 \pm 0.13$ & ND & $<\mathrm{LOD}$ & 26.30 \\
\hline R44 & $\# 41$ & 10.08 .2017 & ND & $4.75 \pm 0.37$ & ND & $5.23 \pm 0.37$ & ND & $<\mathrm{LOD}$ & 13.44 \\
\hline R45 & $\# 42$ & 17.08 .2017 & ND & $5.51 \pm 0.00$ & ND & $5.65 \pm 0.11$ & $\mathrm{G} 1 \mathrm{G} 2 \mathrm{P}[\mathrm{x}]$ & $<\mathrm{LOD}$ & 25.72 \\
\hline R46 & $\# 43$ & 30.08 .2017 & ND & $<\mathrm{LOD}$ & ND & $5.13 \pm 0.18$ & ND & $5.20 \pm 0.07$ & 10.05 \\
\hline R48 & $\# 44$ & 7.09 .2017 & ND & $5.02 \pm 0.17$ & ND & $5.16 \pm 0.00$ & ND & $<\mathrm{LOD}$ & 9.86 \\
\hline R49 & $\# 45$ & 13.09 .2017 & ND & $5.67 \pm 0.06$ & ND & $5.64 \pm 0.09$ & ND & $<\mathrm{LOD}$ & 4.24 \\
\hline R50 & $\# 46$ & 20.09 .2017 & ND & $5.28 \pm 0.08$ & ND & $6.19 \pm 0.09$ & ND & $4.72 \pm 0.13$ & 13.27 \\
\hline
\end{tabular}


Regarding noroviruses, norovirus GII was the most prevalent genogroup as $76 \%$ of the samples (35/46) were positive, while norovirus GI was detected in $69.6 \%$ of the samples (32/46) by RT-qPCR. On average, the load (log PCRU/L) was slightly lower for norovirus GI (5.92 log PCRU/L) than for norovirus GII (6.05 log PCRU/L). Rotavirus was detected by RT-qPCR in 71.7\% of the samples (33/46) with an average load of $6.92 \log$ PCRU/L.

Both norovirus GII and rotavirus showed seasonality in the viral load along the year (Figure 1). The load of norovirus GII was higher during the cold months (October to February) and decreased sharply in spring (March). Interestingly, the months with lower norovirus GII loads were those with higher rotavirus loads (March to June). No seasonality was observed for norovirus GI.

A
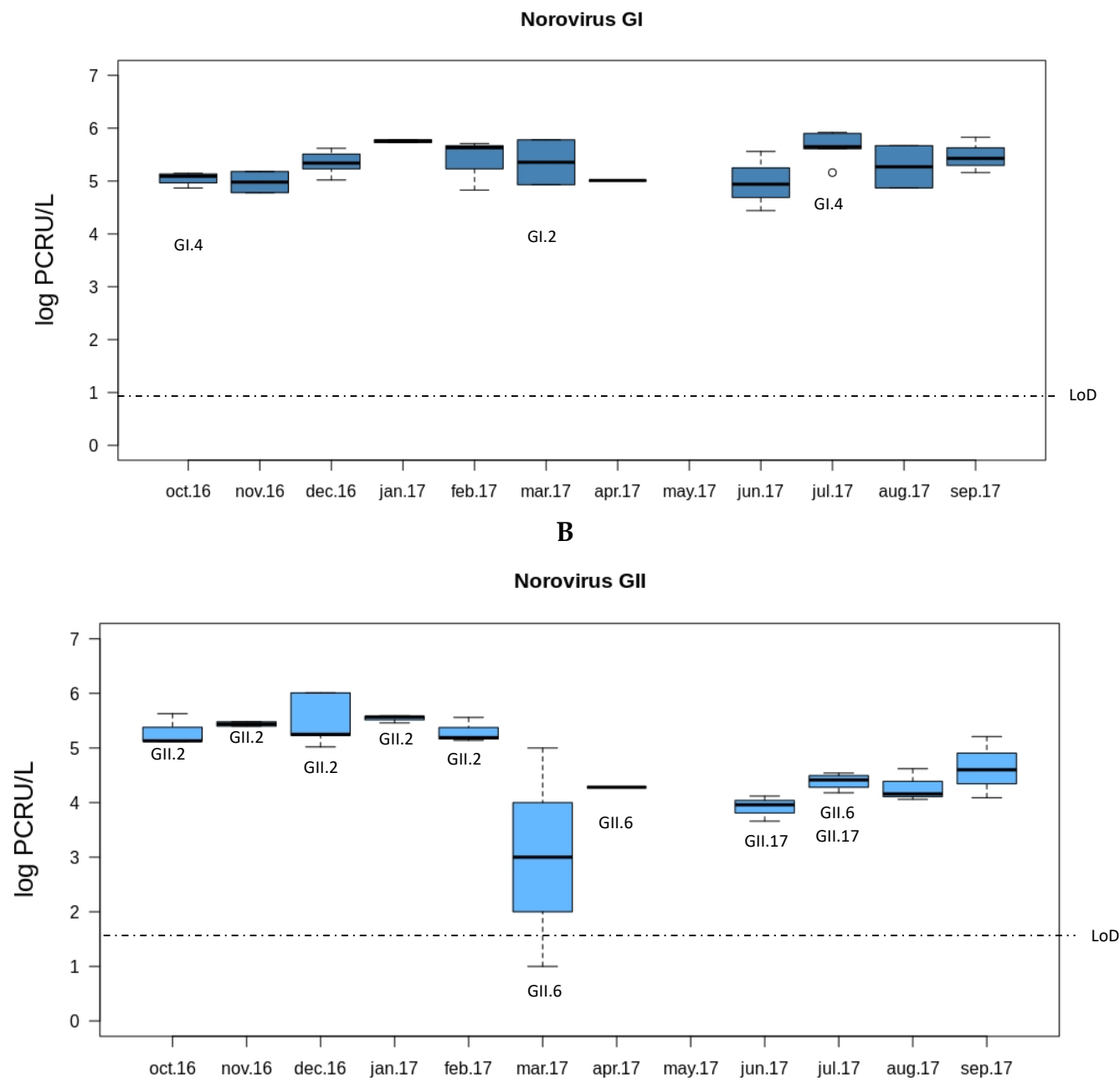

Figure 1. Cont. 


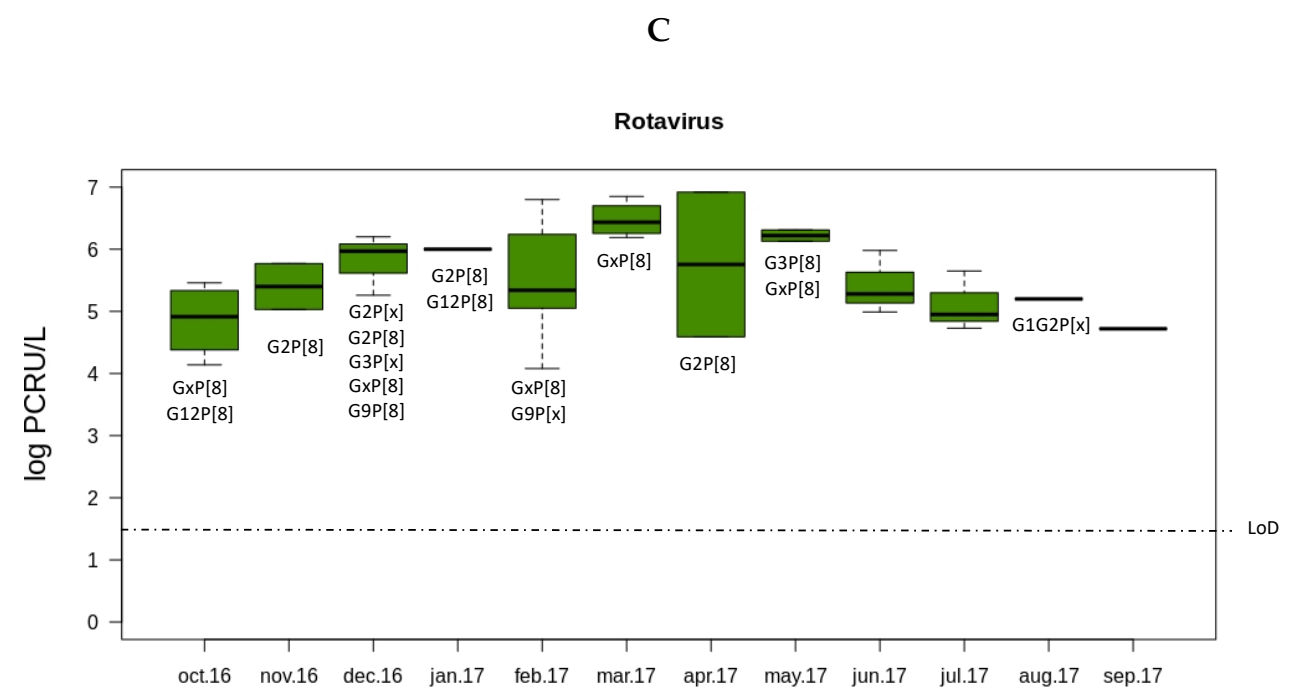

Figure 1. Overview of the concentrations and genotypes of enteric viruses detected in sewage. Boxplots show median concentrations ( $\log$ PCRU/L) with the 25th and 75th percentile values of norovirus GI (A panel in dark blue), norovirus GII (B panel in light blue), and rotavirus (C panel in green). Viral genotypes are indicated according to the month in which the sample was sampled.

\subsection{Rotavirus and Norovirus Genotypes from Sewage Samples}

In order to perform the genotyping of the samples, semi-nested RT-PCR was carried out as described in the Material and Methods section. Of the norovirus positive samples, 13 norovirus GI and 23 norovirus GII could be amplified. In a large number of samples, the genotype could not be determined (ND) even if the samples were positive by both RT-qPCR and semi-nested RT-PCR (Table 3). For the noroviruses GI, only four sequences were obtained out of the 13 seminested PCR positive samples (two sequences belonged to the GI.2 genotype and two to the GI.4 genotype). Within the GII genogroup, the most abundant genotype was the GII.2 (40\%, 14/35). The second most common norovirus genotype was the GII.6 (8.6\%, 3/35), followed by GII.17 (5.7\%, 2/35).

Table 3. Prevalence of norovirus GI, norovirus GII, and rotavirus in sewage samples from Valencia. ND is indicated when the genotype was not determined.

\begin{tabular}{cccccc}
\hline & Norovirus & \multicolumn{3}{c}{ Rotavirus } \\
\hline Genotype & GI (\%) & GII (\%) & Genotype & VP7 (\%) & VP4 (\%) \\
\hline ND & $87.5(28 / 32)$ & $45.7(16 / 35)$ & ND & $63.5(21 / 33)$ & $42.3(14 / 33)$ \\
\hline GI.2 & $6.25(2 / 32)$ & - & P[8] & - & $57.7(19 / 33)$ \\
\hline GI.4 & $6.25(2 / 32)$ & - & G1+G2 & $3(1 / 33)$ & - \\
\hline GII.2 & - & $40(14 / 35)$ & G2 & $15.2(5 / 33)$ & - \\
\hline GII.6 & - & $8.6(3 / 35)$ & G3 & $6.1(2 / 33)$ & - \\
\hline GII.17 & - & $5.7(2 / 35)$ & G9 & $6.1(2 / 33)$ & - \\
\hline & & & G12 & $6.1(2 / 33)$ & - \\
\hline
\end{tabular}

Multiplex semi-nested RT-PCR was performed to study the genotypes of the rotavirus VP7 and VP4 coding genes (G and P genotypes respectively). In this case, $63 \%$ of the samples (29/46) could be amplified for at least one of these two targets. For VP7, the G2 genotype was the most prevalent $(15.2 \%, 5 / 33)$. G3, G9, and G12 were detected with the same percentage, $(6.1 \%, 2 / 33)$, followed by a sample with a mixture of genotypes G1+G2 (3\%, 1/33). For the rotavirus VP4 gene, P[8] was the only genotype obtained in all the samples $(57.7 \%, 19 / 33)$. 


\subsection{Phylogenetic Analyses of Sewage Detected Norovirus VP1 Coding Gene}

Figure 2 shows the phylogenetic tree of norovirus GI capsid sequences obtained in this study. Sequences formed monophyletic groups in the tree and are represented with their corresponding prototype strains within each genotype (GI.2 and GI.4). The degree of nucleotide sequence identity within the GI.2 sequences from this study ranged from $96.7 \%$ to $99.6 \%$, while within the GI.4 sequences ranged from $91.3 \%$ to $100 \%$. Furthermore, the percentage of nucleotide sequence identity between the GI.2 and GI.4 groups was 53.8\% to 59.5\%. Within the GI.4 group, the sequences from samples R3 and R41 shared an identity of 93.2\%. R3 was identical to Pingtung sequence (MF996722.1). Regarding GI.2 group, the sequences from samples R23 and R24 shared an identity of $99.6 \%$.

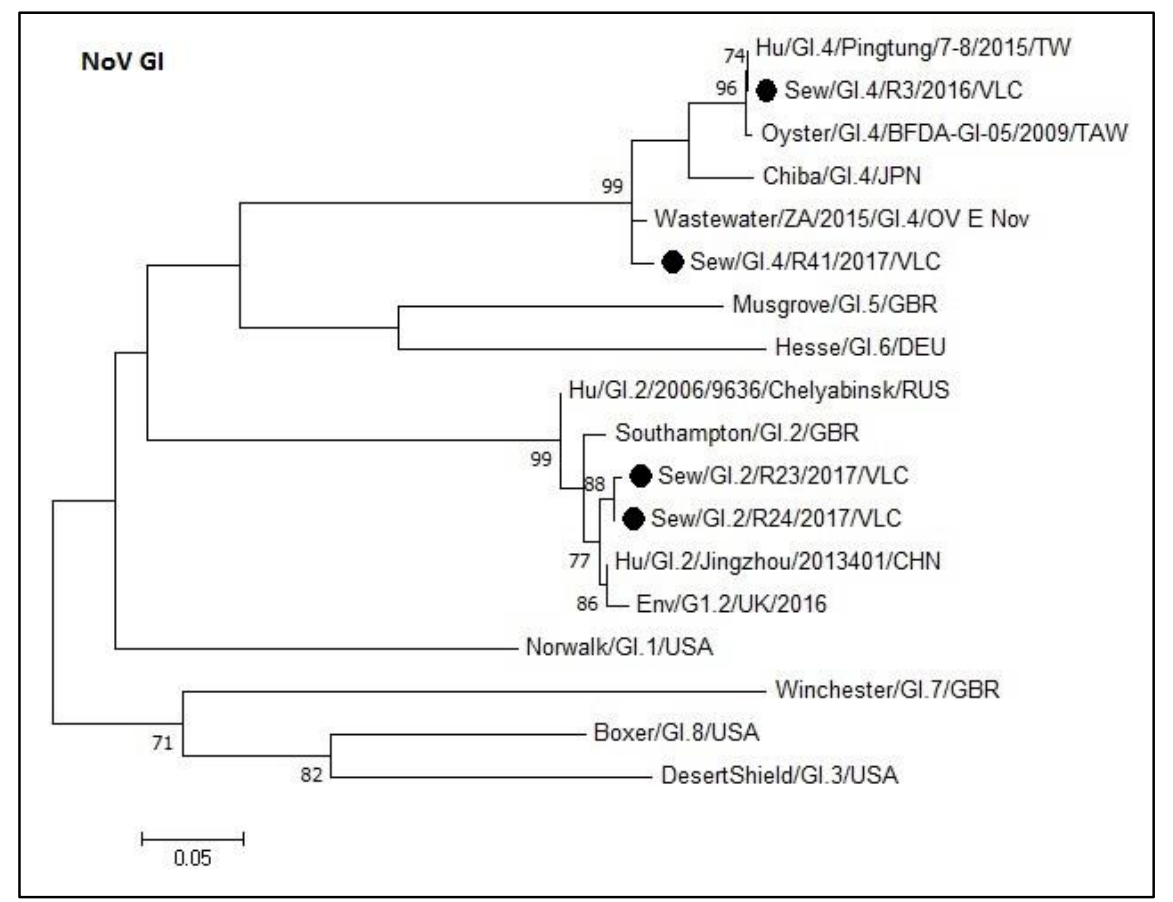

Figure 2. Molecular phylogenetic analysis of norovirus GI capsid. The evolutionary history was inferred using the Maximum Likelihood method based on the Kimura 2-parameter model [42] with a bootstrap of 1000 replicates. The tree is drawn to scale, the branch lengths measure the number of substitutions per site. The analysis included 18 nucleotide sequences. There were 276 positions in the final dataset including nucleotides from 5386 to 5662.

The norovirus GII sequences from this study were divided in three well-supported clusters in the tree, corresponding to the GII.2, GII.6, and GII.17 genotypes (Figure 3). All the GII.2 sewage samples sequences grouped in the same cluster with a degree of identity between $95 \%$ and $100 \%$ compared to the reference strains. As observed in Figure 3, the different boxes include identical sequences ( $a, b$, and c). All the sewage sequences included in the box ' $a$ ' were identical to two recombinant sequences of GII.P16-GII.2 genotype (Kawasaki151-LC215414.1, and Novosibirsk-MG893000.1). The GII.6 cluster grouped sequences with an identity between $88.1 \%$ and $98.9 \%$. This cluster was divided into three subgroups. The first subgroup is composed of R32 and SD2404 (KR107699.1) sequences. The second include the SeaCroft reference sequence (AJ277620) while the last group contains R22, R39, and 14-AG-3 (KM036374.1) sequences. The identity within each subgroup was greater than $97.3 \%$. Regarding the GII.17 cluster, it contains the box ' $c$ ' (100\% of identity) sequences and a different subgroup composed of the reference sequence CSE1 (AY502009). This last sequence shared an identity of $81.3 \%$ with the box ' $c$ ' sequences. 


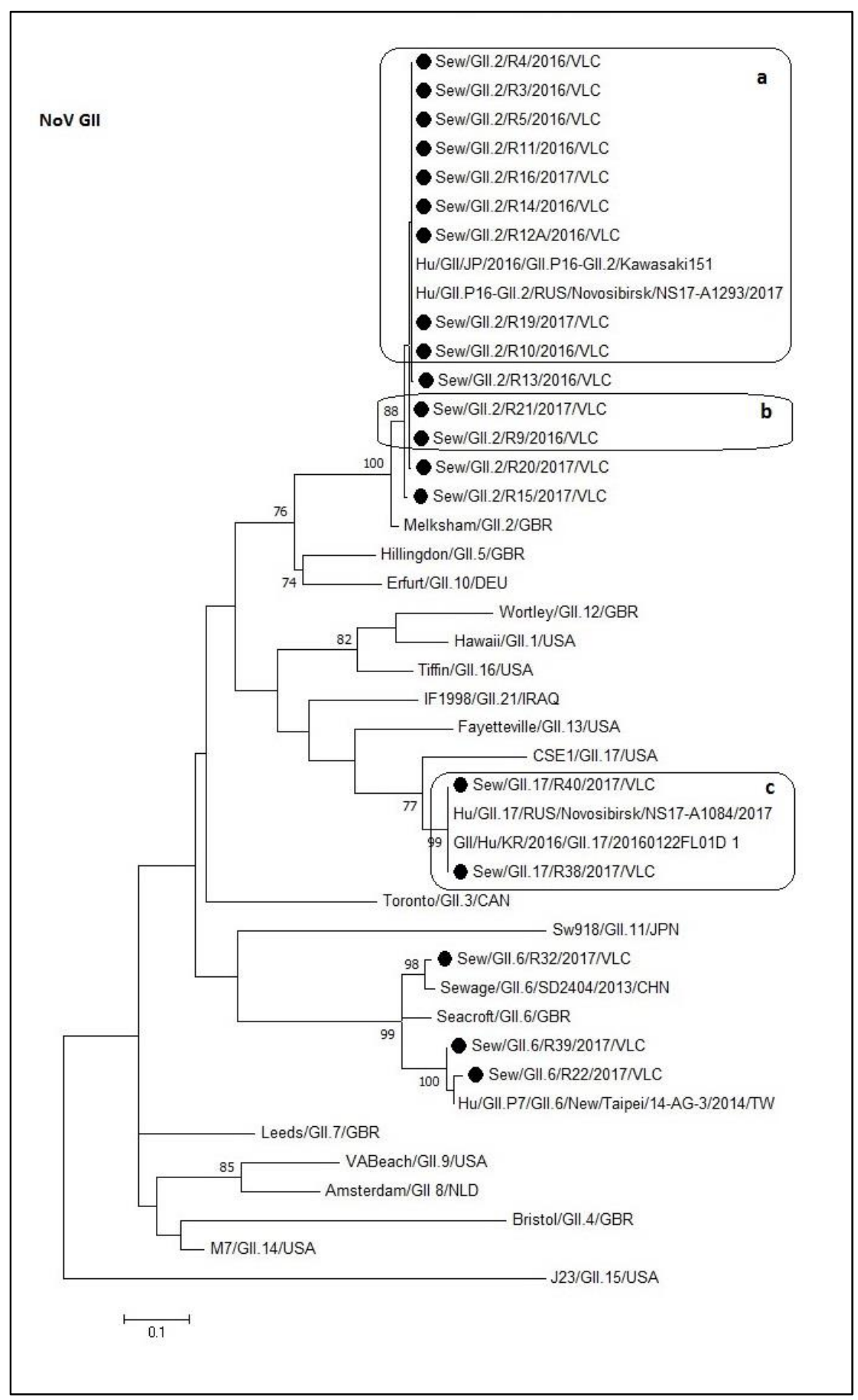

Figure 3. Molecular phylogenetic analysis of norovirus GII capsid. The evolutionary history was inferred by using the Maximum Likelihood method based on the Kimura 2-parameter model [42] with a bootstrap of 1000 replicates. The tree is drawn to scale, the branch lengths measure the number of substitutions per site. The analysis included 43 nucleotide sequences. There were 273 positions in the final dataset including nucleotides from 5113 to 5386 . a, b, and c: Boxes that contain identical sequences.

\subsection{Phylogenetic Analyses of Sewage Detected Rotavirus VP4 and VP7 Coding Genes}

For the P[8] dendrogram of the rotavirus VP4 gene, all rotavirus sequences clustered within the lineage III (Figure 4). The nucleotide identity ranged from $92.7 \%$ to $100 \%$. Sequences within $a, b$, and c boxes shared a 100\% identity. Moreover, R32 is the same sequence like the PR204 Italian strain 
(KT988219.1). Nevertheless, the lower percentage of identity between sewage sample (lineage III) and reference sequences of different lineage was with lineage IV (73.1-82.8\%). The nucleotide identity between the VP4 sequence of sewage samples and the vaccine strains was high, but not complete, RotaTeq ${ }^{\circledR}$ shared an identity range of $90-95 \%$ and Rotarix ${ }^{\circledR}$ shared an identity range of $84-90 \%$.

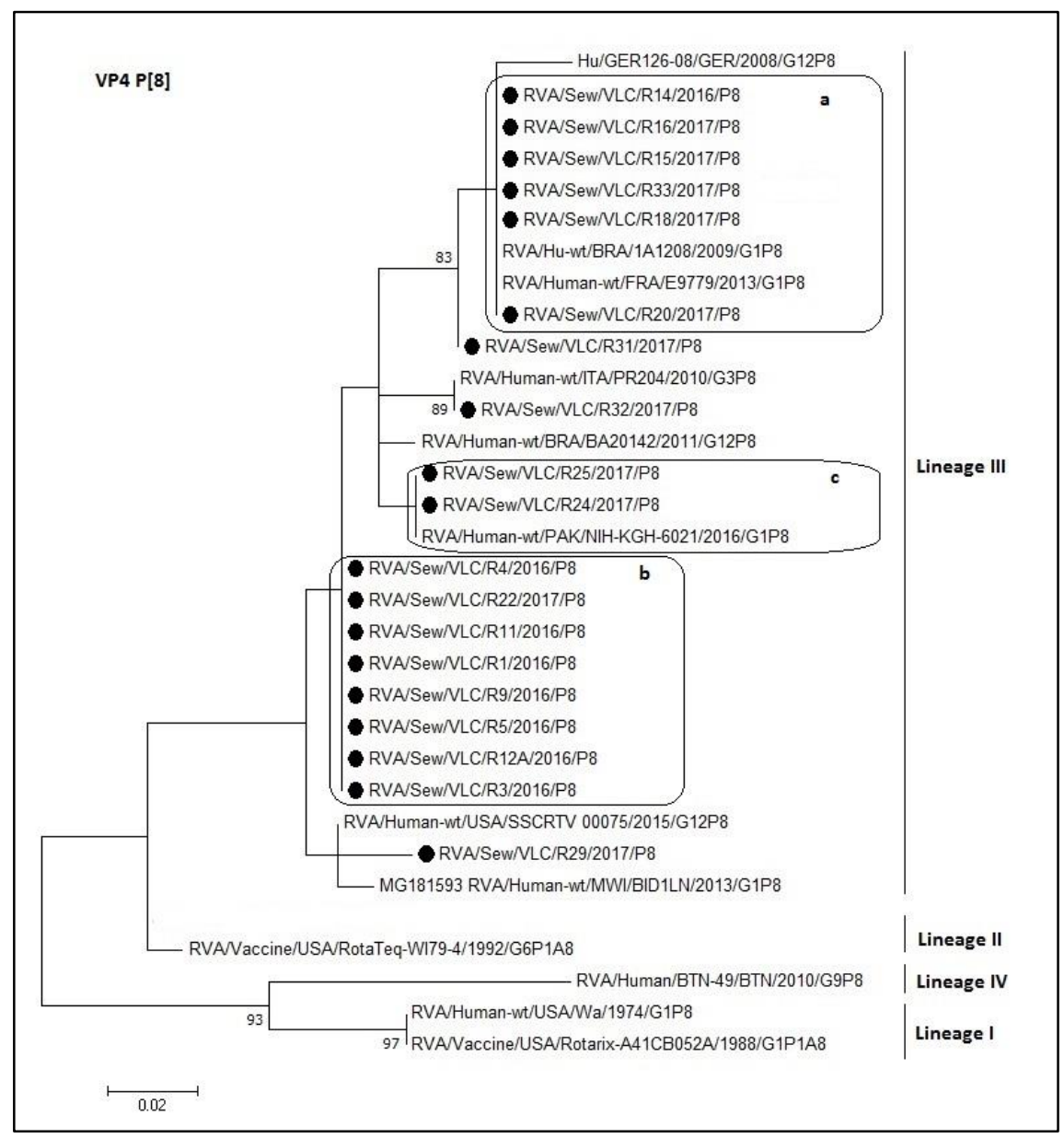

Figure 4. Molecular phylogenetic analysis of P[8] rotavirus (VP4 gene). The evolutionary history was inferred by using the Maximum Likelihood method based on the Tamura 3-parameter model [43] with a bootstrap of 1000 replicates. The tree is drawn to scale, the branch lengths measure the number of substitutions per site. The analysis included 32 nucleotide sequences. There were 127 positions in the final dataset. including nucleotides from 180 to 307. a, b, and c: Boxes containing identical sequences.

Phylogenetic analysis of the VP7 coding gene of the rotavirus sequences was divided into five trees (each one for each of the sequenced genotypes G1, G2, G3, G9, and G12; Figures 5-9, respectively). The R45 sample possessed a mixture of G1 and G2 genotypes. Figure 5 shows the tree of the G1 genotype. R45 grouped with sequences belonging to lineage I (nucleotide identity 99.3-99.8\%). In this case, Rotarix ${ }^{\circledR}$ was the vaccine strain with higher percentage of identity with the sewage sequence R45 $(94 \%)$ while Rotateq ${ }^{\circledR}$ shared an identity of $86 \%$.

The rotavirus G2 genotype is shown in Figure 6. All sewage samples belonged to lineage IV (identity 96-100\%). The R12A sequence grouped in a different cluster than the other sewage sequences. The percentage of identity between RotaTeq ${ }^{\circledR}$ vaccine strain and the sewage samples ranged from $93 \%$ to $94 \%$. 


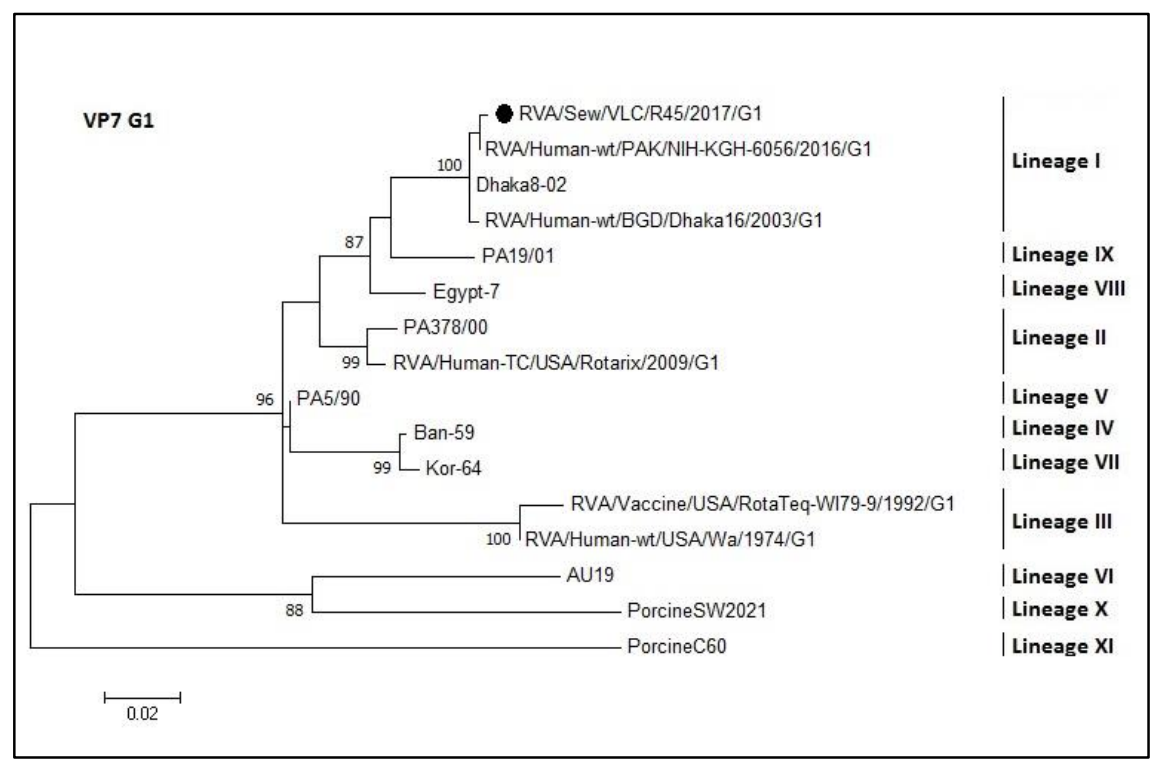

Figure 5. Molecular phylogenetic analysis of G1 rotavirus (VP7 gene). The evolutionary history was inferred by using the Maximum Likelihood method based on the Tamura 3-parameter model [43] with a bootstrap of 1000 replicates. The tree is drawn to scale, the branch lengths measure the number of substitutions per site. The analysis included 16 nucleotide sequences. There were 416 positions in the final dataset including nucleotides from 358 to 774 .

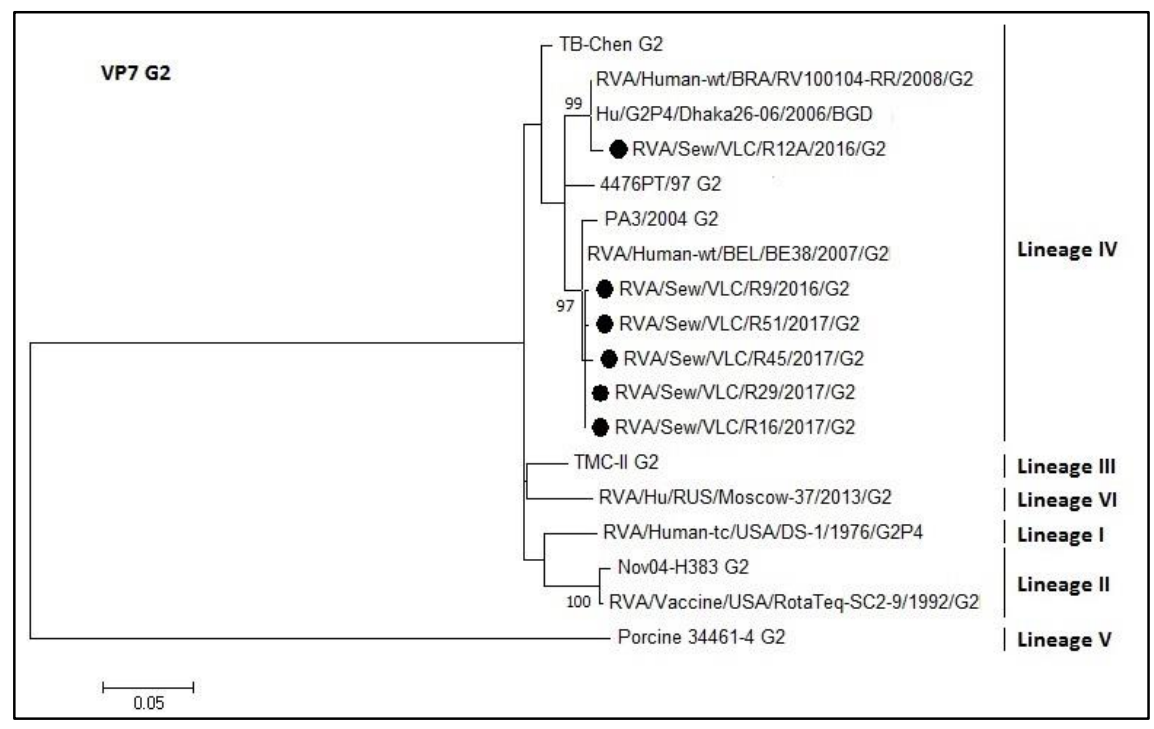

Figure 6. Molecular phylogenetic analysis of G2 rotavirus (VP7 gene). The evolutionary history was inferred by using the Maximum Likelihood method based on the Tamura 3-parameter model [43] with a bootstrap of 1000 replicates. The tree is drawn to scale, the branch lengths measure the number of substitutions per site. The analysis included 18 nucleotide sequences. There was a total of 460 positions in the final dataset including nucleotides from 424 to 884 .

Figure 7 represents the phylogenetic tree of the G3 rotavirus genotype. The two sewage samples sequences (R13 and R31) clustered into lineage I (nucleotide identity 90-100\%) although grouped into two different subgroups. The R31 sequence and the PR1015 (Italian sequence (KT988295.1)) shared a $100 \%$ nucleotide sequence identity. The R13 sequence grouped with a sequence belonging to a Japanese strain isolated from cat (FRV317, access number LC328208.1). On the other hand, RotaTeq ${ }^{\circledR}$ G3 vaccine strain shared an identity of $93 \%$ and $96 \%$ with R13 and R31, respectively. 


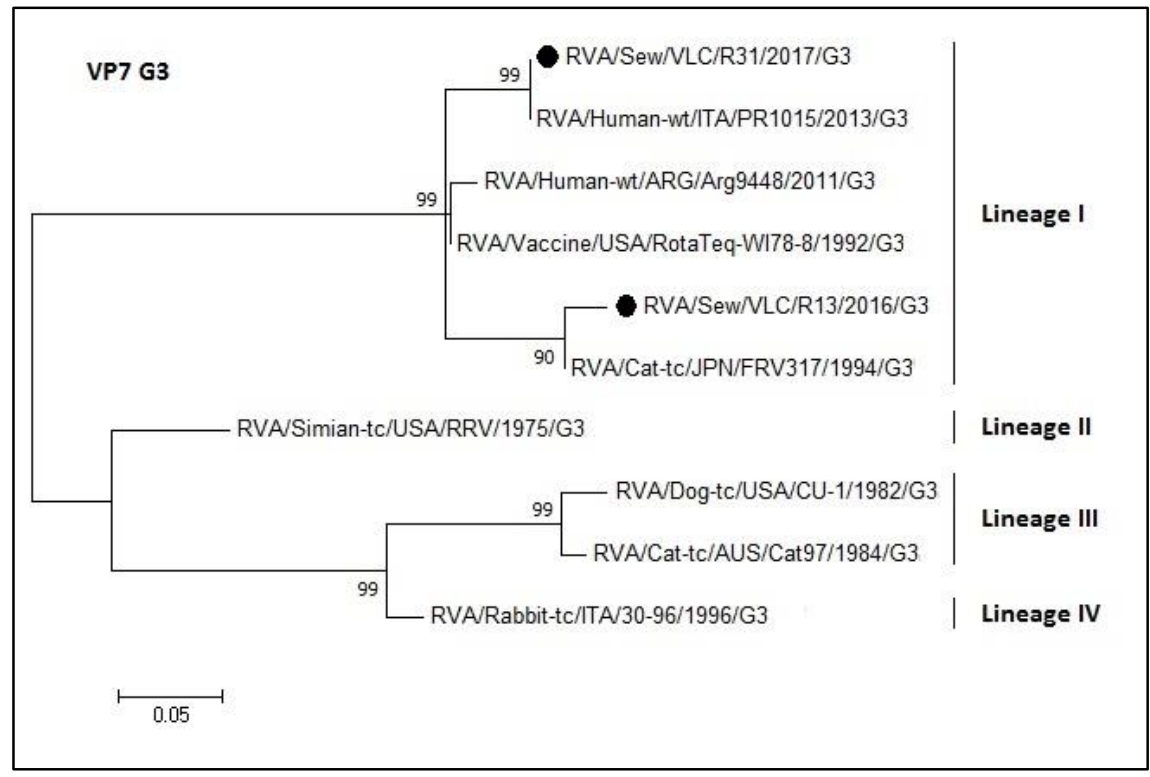

Figure 7. Molecular phylogenetic analysis of G3 rotavirus (VP7 gene). The evolutionary history was inferred by using the Maximum Likelihood method based on the Tamura 3-parameter model [43] with a bootstrap of 1000 replicates. The tree is drawn to scale, the branch lengths measure the number of substitutions per site. The analysis included 10 nucleotide sequences. There was a total of 159 positions in the final dataset including nucleotides from 774 to 933.

For the G9 dendrogram of the VP7 gene, the two sequences from sewage samples grouped in lineage III (Figure 8) sharing an identity of $94-98.7 \%$. The R13 sample was typed as G9 by the multiplex PCR but by sequencing resulted to be an outgroup in that phylogenetic tree (G9 genotype) and was confirmed to be a G3 genotype (Figure 7).

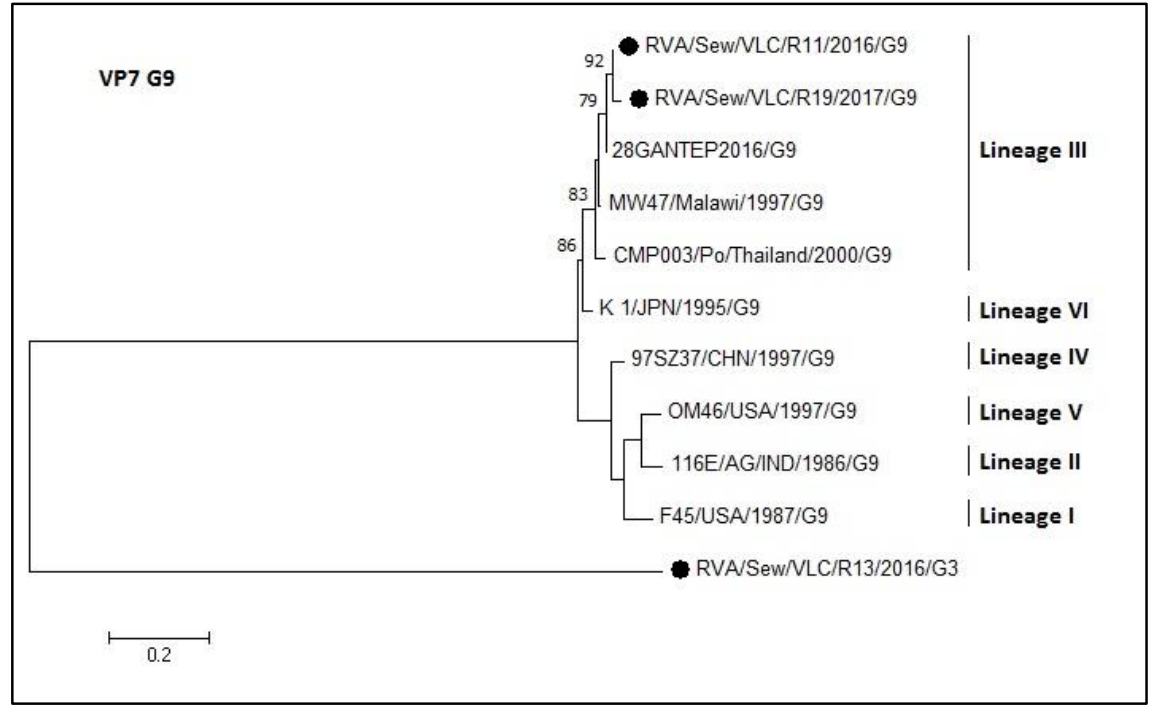

Figure 8. Molecular phylogenetic analysis of G9 rotavirus (VP7 gene). The evolutionary history was inferred by using the Maximum Likelihood method based on the Tamura 3-parameter model [43] with a bootstrap of 1000 replicates. The tree is drawn to scale, the branch lengths measure the number of substitutions per site. The analysis included 11 nucleotide sequences. There was a total of 159 positions in the final dataset including nucleotides from 774 to 933.

The phylogenetic relationships of the G12 genotype are represented in Figure 9. The samples R5 and R15 have the same sequence and 100\% nucleotide identity with a strain from India (HRB79; 
access number KC416951) and with a Brazilian strain (1A2518 access number KX932477.1). The sewage sample sequences belonged to lineage III.

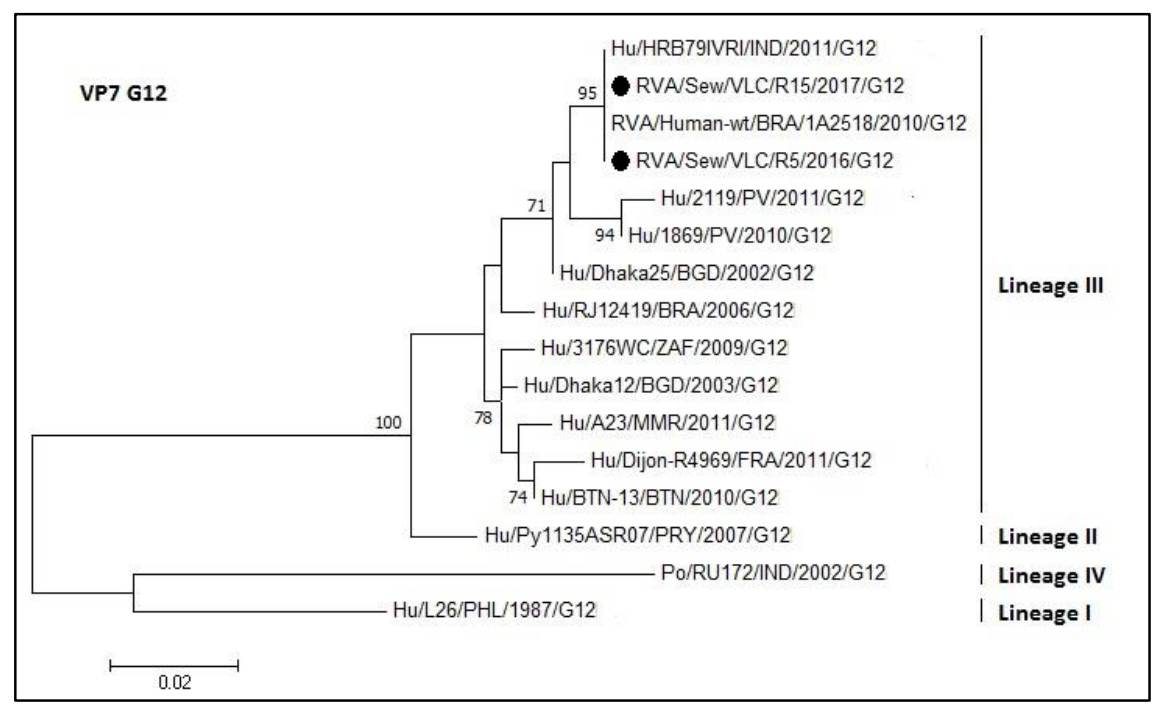

Figure 9. Molecular phylogenetic analysis of G12 rotavirus (VP7 gene). The evolutionary history was inferred by using the Maximum Likelihood method based on the Tamura 3-parameter model [43] with a bootstrap of 1000 replicates. The tree is drawn to scale, the branch lengths measure the number of substitutions per site. The analysis involved 16 nucleotide sequences. There was a total of 378 positions in the final dataset including nucleotides from 584 to 926.

\section{Discussion}

Sewage is an important source to study the epidemiology of viral pathogens transmitted by the faecal-oral route, especially when routine viral detection is not performed in outpatients or hospital facilities. The present study provided an overview of the epidemiology of noroviruses and rotaviruses through the analysis of sewage samples collected in Valencia from September 2016 to September 2017. In the present study, ultracentrifugation was selected as the concentration methodology since it was previously applied by our team successfully $[18,22,24]$ and its performance showed to be comparable to other methods such as aluminium hydroxide adsorption-precipitation procedure [26]. Currently, RT-qPCR is the golden standard used to study viral loads $[26,44,45]$ from sewage samples but next generation sequencing (NGS) methodologies have emerged strongly in the field in two modalities, sequencing the total virome with or without enrichment [46-48] and the NGS sequencing of PCR amplicons [49].

The present study has shown that both noroviruses and rotaviruses are widely disseminated $(76 \%$ norovirus GII, $69.6 \%$ norovirus GI, and 71.7\% rotaviruses) in the Valencian sewage and viral loads varied from 4.33 to $5.75 \log$ PCRU/L, 4.69 to $6.95 \mathrm{log}$, and 4.08 to $6.92 \log$ PCRU/L for norovirus GI, GII, and rotavirus, respectively.

For many of the positive samples obtained after conventional semi-nested RT-PCR, samples could not be genotyped due to mixed electropherograms. This fact may be due to the presence of more than one genotype in the same sample (a common trend in environmental samples). Despite this, the methodology applied allowed us to identify several noroviruses GI and GII. It is known that noroviruses GII have a wider circulation than noroviruses GI, playing a major role in acute gastroenteritis [15]. In the present study the capsid region that defines the norovirus genotype was targeted [9]. Most strains resulted to be of genogroup II, reflecting the higher circulation of the genogroup in the population [15].

In the last decades, the GII.4 noroviruses have been the most prevalent genotype infecting humans followed by others such as GII.2, GII.16, and GII.17 [9,50-53]. In the phylogeny of the norovirus GII 
(Figure 3) it can be observed that the GII.2 sequences grouped together with reference sequences of the recombinant genotype GII.P16-GII.2. Genetic recombination frequently occurs in RNA viruses and, since the first description of a naturally occurring norovirus recombination in 1997 [54], recombinant norovirus have been reported worldwide, including the region of Valencia [55]. Different studies have revealed an emergence of GII.P16-GII.2 recombinant strain in 2016 in different parts of the world [56-59]. This recombinant strain could become the currently predominant variant and be responsible for upcoming outbreaks of acute gastroenteritis caused by noroviruses. Monitoring of noroviruses in sewage is useful for the sensitive detection of epidemic variants in human populations.

It is known that rotaviruses causes disease in children younger than 5 years of age, especially in neonates and up to 2 years of age [60]. Therefore, most viruses remain in the diapers and do not travel into the sewage. This implies that the detected rotaviruses might be infecting older children and adults, probably asymptomatically. The large diversity of rotaviruses observed worldwide would theoretically allow up to 800 types of G- and P-type combinations, resulting in a wide variety of rotaviruses with different antigenic combinations [15]. In addition, it is possible to find mixed genotypes in which several $\mathrm{G}$ and/or P types are combined. This wide diversity can be generated by various mechanisms [61-63], which may lead to antigenic changes: Human-to-human or animal-to-human reassortments, interspecies transmission of rotavirus among multiple hosts, genetic drift, genetic recombination between different rotavirus strains, and inter- or intra-genic recombination. However, despite the wide antigenic and genomic variety of rotavirus, over the past three decades $90 \%$ of the strains identified in humans worldwide have presented the G1P[8], G2P[4], G3P[8], G4P[8], G9P[8], and G12P[8] genotypes, with different variations in geographic and temporal distribution [62,64-67]. The sewage rotavirus strains characterized in the present study belong to the P[8] lineage III, a lineage different from the vaccine strains Rotarix (P[8] lineage I) and RotaTeq- WI79-4 (P[8] lineage II). In addition, the P[8]-III strains segregated into distinct sub clusters (Figure 4). P[8] is currently the most common genotype infecting humans [64]. On the other hand, we can observe that sequences of the group ' $a$ ' (Figure 4 box 'a') share 100\% identity with strains that have been circulating prior to this study (with the Brazilian strain 1A1208, 2009; and with the French strain E9779, 2013).

Interestingly, the R29 sample presented the G2P[8] combination. The recombination between G2 and $\mathrm{P}[8]$ is considered unusual. Figure 4 shows that the VP8* sequence of the R29 sample groups in a different cluster than the rest of the P[8] sequences (lineage III). Furthermore, the similarity between R29 and the rest of the sequences of lineage III presented a range between 92.7\% (GER126-08) and 98.3\% (SSCRTV_00075), the latter grouped in the same cluster. These identity percentages are lower than expected for sequences from a nearby common ancestor, where the most likely evolutionary mechanism is due to genetic drift. Interestingly, R29 obtained a higher identity with the RotaTeq vaccine strain (93.5\%), belonging to lineage II, than with the GER1236-08 strain, belonging to lineage III. These data suggest a different mechanism of evolution and different origin of R29 strain compared to the rest of strains of lineage III. Thus, R29 cluster could constitute a sub-lineage of the lineage III, even a new lineage.

When the strains of this study were compared with vaccine strains the similarity of the deduced amino acid sequences was higher than nucleotide sequences. Regarding P[8] sequences, vaccines strains shared a similarity range of 95.1-97.6\% with the strains analyzed. Within G1 genotype, the sequences of the sewage samples shared between $95.6 \%$ and $97.8 \%$ similarity with RotaTeq and Rotarix strains, respectively. In regard to G2 genotype, the similarity was 96.2-98.1\%. Finally, the G3 genotype analyses of similarity showed a $95.6 \%$ identity between the RotaTeq strain and the sewage strains. These data suggest a high preservation of the function and structure of antigenic epitopes between these strains.

The relationship between the genotypes of rotavirus and norovirus detected in sewage water and the clinical isolates are unclear, since there are not published data on the epidemiology of clinical samples in this region for the studied period. However, we recently published the rotavirus clinical data for the period 2013-2015 [68] where the P[8] was the predominant genotype responsible of 97.7\% 
of the clinical cases caused by rotavirus and was combined with G9 (49.6\%), G1 (20.3\%), and G12 (14.3\%) VP7 genotypes. Interestingly, during 2013-2015 only $1.5 \%$ of the samples where G2 and this is the genotype with a higher prevalence in sewage in the period 2016-2017. This might be due to a shift in the circulating genotypes in the population, to a higher stability of the G2 genotype in environmental samples or to the existence of a higher proportion of asymptomatic infections of rotaviruses of the G2 genotype compared to the G1, G9, and G12 genotypes.

As a conclusion, the results presented here show that the monitoring of noroviruses and rotaviruses in sewage is useful to study the molecular epidemiology of those viruses in a given population.

Author Contributions: Conceptualization, J.R.D. and G.S.-B.; Methodology, C.S.-B., W.R., A.P.-C., S.V.-V., R.G.-R., C.M., and J.B.; Writing-Original Draft Preparation, C.S., W.R., G.S., and J.R.D.; Review \& Editing, A.P.-C., S.V.-V., R.G.-R., C.M., and J.B.; Project Administration J.R.D. and G.S.; Funding Acquisition, G.S. and J.R.D. All authors have read and agreed to the published version of the manuscript.

Funding: This work was supported by Spanish Government (Ministerio de Economía y Competitividad) grants AGL2017-84165-C2-2-R, RYC-2013-12442, and AGL2017-82909-R (AEI/FEDER, UE) funded by Spanish Ministry of Science, Innovation and Universities. This work was also founded by the Generalitat Valenciana and the UE FEDER program IDIFER/2018/056. CSB is the recipient of a predoctoral grant FPI from the Spanish Government RE2018-083315. RGR and WR are supported by postdoctoral fellowships from Valencian Government (APOST/2017/037 and APOSTD/2018/150).

Acknowledgments: The authors acknowledge the Entidad de Saneamiento de Aguas Residuales (EPSAR) and Global Omnium S.L. the access to sewage and their aid in sampling at EDAR Quart Benager.

Conflicts of Interest: The authors declare no conflict of interest.

\section{References}

1. GBD 2015 Mortality; Causes of Death Collaborators. Global, regional, and national life expectancy, all-cause mortality, and cause-specific mortality for 249 causes of death, 1980-2015: A systematic analysis for the Global Burden of Disease Study 2015. Lancet 2016, 388, 1459-1544. [CrossRef]

2. Bartnicki, E.; Cunha, J.B.; Kolawole, A.O.; Wobus, C.E. Recent advances in understanding noroviruses. F1000Research 2017, 6, 1-9. [CrossRef] [PubMed]

3. Patel, M.M.; Widdowson, M.A.; Glass, R.I.; Akazawa, K.; Vinjé, J.; Parashar, U.D. Systematic literature review of role of noroviruses in sporadic gastroenteritis. Emerg. Infect. Dis. 2008, 14, 1224-1231. [CrossRef] [PubMed]

4. Kauppinen, A.; Miettinen, I. Persistence of Norovirus GII Genome in Drinking Water and Wastewater at Different Temperatures. Pathogens 2017, 6, 48. [CrossRef] [PubMed]

5. Seitz, S.R.; Leon, J.S.; Schwab, K.J.; Lyon, G.M.; Dowd, M.; McDaniels, M.; Abdulhafid, G.; Fernandez, M.L.; Lindesmith, L.C.; Baric, R.S.; et al. Norovirus Infectivity in Humans and Persistence in Water. Appl. Environ. Microbiol. 2011, 77, 6884-6888. [CrossRef] [PubMed]

6. Teunis, P.F.M.; Moe, C.L.; Liu, P.; Miller, S.E.; Lindesmith, L.; Baric, R.S.; Le Pendu, J.; Calderon, R.L. Norwalk virus: How infectious is it? J. Med. Virol. 2008, 80, 1468-1476. [CrossRef]

7. Havelaar, A.H.; Kirk, M.D.; Torgerson, P.R.; Gibb, H.J.; Hald, T.; Lake, R.J.; Praet, N.; Bellinger, D.C.; de Silva, N.R.; Gargouri, N.; et al. World Health Organization Global Estimates and Regional Comparisons of the Burden of Foodborne Disease in 2010. PLoS Med. 2015, 12, e1001923. [CrossRef]

8. Lopman, B.A.; Steele, D.; Kirkwood, C.D.; Parashar, U.D. The Vast and Varied Global Burden of Norovirus: Prospects for Prevention and Control. PLoS Med. 2016, 13, e1001999. [CrossRef]

9. Chhabra, P.; de Graaf, M.; Parra, G.I.; Chan, M.C.-W.; Green, K.; Martella, V.; Wang, Q.; White, P.A.; Katayama, K.; Vennema, H.; et al. Updated classification of norovirus genogroups and genotypes. J. Gen. Virol. 2019, 100. [CrossRef]

10. Fauquet, C.M.; Mayo, M.a.; Maniloff, J.; Desselberger, U.; Ball, L.a. Virus Taxonomy: VIIIth Report of the International Committee on Taxonomy of Viruses. Virus Res. 2005.

11. Xi, J.; Graham, D.; Wang, K.; Estes, M. Norwalk virus genome cloning and characterization. Science 1990, 250, 1580-1583. [CrossRef] [PubMed]

12. Prasad, B.V.V.; Hardy, M.E.; Dokland, T.; Bella, J.; Rossmann, M.G.; Estes, M.K. X-ray Crystallographic Structure of the Norwalk Virus Capsid. Science 1999, 286, 287-290. [CrossRef] [PubMed] 
13. Matthijnssens, J.; Ciarlet, M.; McDonald, S.M.; Attoui, H.; Bányai, K.; Brister, J.R.; Buesa, J.; Esona, M.D.; Estes, M.K.; Gentsch, J.R.; et al. Uniformity of rotavirus strain nomenclature proposed by the Rotavirus Classification Working Group (RCWG). Arch. Virol. 2011, 156, 1397-1413. [CrossRef] [PubMed]

14. RCWG Rotavirus Classification Working Group. Available online: https://rega.kuleuven.be/cev/ viralmetagenomics/virus-classification/rcwg (accessed on 7 November 2019).

15. Buesa, J.; Rodriguez-Díaz, J. The Molecular Virology of Enteric Viruses. In Viruses in Foods; Springer International Publishing: Cham, Switzerland, 2016; pp. 59-130.

16. Lodder, W.J.; de Roda Husman, A.M. Presence of Noroviruses and Other Enteric Viruses in Sewage and Surface Waters in The Netherlands. Appl. Environ. Microbiol. 2005, 71, 1453-1461. [CrossRef] [PubMed]

17. Katayama, H.; Haramoto, E.; Oguma, K.; Yamashita, H.; Tajima, A.; Nakajima, H.; Ohgaki, S. One-year monthly quantitative survey of noroviruses, enteroviruses, and adenoviruses in wastewater collected from six plants in Japan. Water Res. 2008, 42, 1441-1448. [CrossRef] [PubMed]

18. Rodriguez-Diaz, J.; Querales, L.; Caraballo, L.; Vizzi, E.; Liprandi, F.; Takiff, H.; Betancourt, W.Q. Detection and Characterization of Waterborne Gastroenteritis Viruses in Urban Sewage and Sewage-Polluted River Waters in Caracas, Venezuela. Appl. Environ. Microbiol. 2009. [CrossRef]

19. Bosch, A.; Guix, S.; Sano, D.; Pintó, R.M. New tools for the study and direct surveillance of viral pathogens in water. Curr. Opin. Biotechnol. 2008, 19, 295-301. [CrossRef]

20. Pérez-Sautu, U.; Sano, D.; Guix, S.; Kasimir, G.; Pintó, R.M.; Bosch, A. Human norovirus occurrence and diversity in the Llobregat river catchment, Spain. Environ. Microbiol. 2012, 14, 494-502. [CrossRef]

21. Miagostovich, M.P.; Ferreira, F.F.M.; Guimaraes, F.R.; Fumian, T.M.; Diniz-Mendes, L.; Luz, S.L.B.; Silva, L.A.; Leite, J.P.G. Molecular Detection and Characterization of Gastroenteritis Viruses Occurring Naturally in the Stream Waters of Manaus, Central Amazonia, Brazil. Appl. Environ. Microbiol. 2008, 74, 375-382. [CrossRef]

22. Betancourt, W.Q.; Querales, L.; Sulbaran, Y.F.; Rodriguez-Diaz, J.; Caraballo, L.; Pujol, F.H. Molecular Characterization of Sewage-Borne Pathogens and Detection of Sewage Markers in an Urban Stream in Caracas, Venezuela. Appl. Environ. Microbiol. 2010. [CrossRef]

23. Cuevas-Ferrando, E.; Randazzo, W.; Pérez-Cataluña, A.; Sánchez, G. HEV Occurrence in Waste and Drinking Water Treatment Plants. Front. Microbiol. 2020, 10, 2937. [CrossRef] [PubMed]

24. Alcala, A.; Vizzi, E.; Rodriguez-Diaz, J.; Zambrano, J.L.; Betancourt, W.; Liprandi, F. Molecular Detection and Characterization of Aichi Viruses in Sewage-Polluted Waters of Venezuela. Appl. Environ. Microbiol. 2010, 76, 4113-4115. [CrossRef] [PubMed]

25. Sánchez, G.; Elizaquível, P.; Aznar, R. A single method for recovery and concentration of enteric viruses and bacteria from fresh-cut vegetables. Int. J. Food Microbiol. 2012, 152, 9-13. [CrossRef]

26. Randazzo, W.; Piqueras, J.; Evtoski, Z.; Sastre, G.; Sancho, R.; Gonzalez, C.; Sánchez, G. Interlaboratory Comparative Study to Detect Potentially Infectious Human Enteric Viruses in Influent and Effluent Waters. Food Environ. Virol. 2019, 11, 350-363. [CrossRef] [PubMed]

27. ISO/TS. Microbiology of Food and Animal Feed. Horizontal Method for Determination of Hepatitis A Virus and Norovirus in Food Using Real-Time RT-PCR Title; ISO/TS: Geneva, Switzerland, 2013.

28. ISO/TS. Microbiology of Food and Animal Feed. Horizontal Method for Determination of Hepatitis A Virus and Norovirus in Food Using Real-time RT-PCR. Part 1: Method for Quantification; ISO/TS: Geneva, Switzerland, 2017.

29. Jothikumar, N.; Kang, G.; Hill, V.R. Broadly reactive TaqMan ${ }^{\circledR}$ assay for real-time RT-PCR detection of rotavirus in clinical and environmental samples. J. Virol. Methods 2009, 155, 126-131. [CrossRef]

30. Pinto, R.M.; Costafreda, M.I.; Bosch, A. Risk Assessment in Shellfish-Borne Outbreaks of Hepatitis A. Appl. Environ. Microbiol. 2009, 75, 7350-7355. [CrossRef]

31. Randazzo, W.; Piqueras, J.; Rodríguez-Díaz, J.; Aznar, R.; Sánchez, G. Improving efficiency of viability-qPCR for selective detection of infectious HAV in food and water samples. J. Appl. Microbiol. 2017, 124, 958-964. [CrossRef]

32. Randazzo, W.; López-Gálvez, F.; Allende, A.; Aznar, R.; Sánchez, G. Evaluation of viability PCR performance for assessing norovirus infectivity in fresh-cut vegetables and irrigation water. Int. J. Food Microbiol. 2016, 229, 1-6. [CrossRef]

33. Eurorotanet EuroRotaNet. Available online: https://www.eurorotanet.com/project-information/documentsand-methods/ (accessed on 8 October 2019). 
34. Iturriza-Gómara, M.; Kang, G.; Gray, J. Rotavirus genotyping: Keeping up with an evolving population of human rotaviruses. J. Clin. Virol. 2004, 31, 259-265. [CrossRef]

35. Kageyama, T.; Shinohara, M.; Uchida, K.; Fukushi, S.; Hoshino, F.B.; Kojima, S.; Takai, R.; Oka, T.; Takeda, N.; Katayama, K. Coexistence of multiple genotypes, including newly identified genotypes, in outbreaks of gastroenteritis due to Norovirus in Japan. J. Clin. Microbiol. 2004, 42, 2988-2995. [CrossRef]

36. Kojima, S.; Kageyama, T.; Fukushi, S.; Hoshino, F.B.; Shinohara, M.; Uchida, K.; Natori, K.; Takeda, N.; Katayama, K. Genogroup-specific PCR primers for detection of Norwalk-like viruses. J. Virol. Methods 2002, 100, 107-114. [CrossRef]

37. Hall, T.A. BioEdit: A user-friendly biological sequence alignment editor and analysis program for Windows 95/98/NT. Nucleic Acids Symp. Ser. 1999.

38. Larkin, M.A.; Blackshields, G.; Brown, N.P.; Chenna, R.; Mcgettigan, P.A.; McWilliam, H.; Valentin, F.; Wallace, I.M.; Wilm, A.; Lopez, R.; et al. Clustal W and Clustal X version 2.0. Bioinformatics 2007, 23, 2947-2948. [CrossRef] [PubMed]

39. Nicholas, K.B.; Nicholas, H.B., Jr. GeneDoc: A tool for editing and annotating multiple sequence alignments. IEEE Softw. 1997.

40. Kumar, S.; Stecher, G.; Tamura, K. MEGA7: Molecular Evolutionary Genetics Analysis Version 7.0 for Bigger Datasets. Mol. Biol. Evol. 2016, 33, 1870-1874. [CrossRef] [PubMed]

41. Felsenstein, J. Evolutionary trees from DNA sequences: A maximum likelihood approach. J. Mol. Evol. 1981, 17, 368-376. [CrossRef] [PubMed]

42. Kimura, M. A simple method for estimating evolutionary rates of base substitutions through comparative studies of nucleotide sequences. J. Mol. Evol. 1980, 16, 111-120. [CrossRef]

43. Tamura, K. Estimation of the number of nucleotide substitutions when there are strong transition-transversion and G+C-content biases. Mol. Biol. Evol. 1992, 9, 678-687.

44. Hoque, S.A.; Thongprachum, A.; Takanashi, S.; Mostafa, S.M.; Saito, H.; Anwar, K.S.; Nomura, A.; Hoque, S.A.; Begum, R.; Sultana, U.N.; et al. Alarming Situation of Spreading Enteric Viruses Through Sewage Water in Dhaka City: Molecular Epidemiological Evidences. Food Environ. Virol. 2019, 11, 65-75. [CrossRef]

45. Randazzo, W.; Khezri, M.; Ollivier, J.; Le Guyader, F.S.; Rodríguez-Díaz, J.; Aznar, R.; Sánchez, G. Optimization of PMAxx pretreatment to distinguish between human norovirus with intact and altered capsids in shellfish and sewage samples. Int. J. Food Microbiol. 2018, 266, 1-7. [CrossRef]

46. Strubbia, S.; Phan, M.V.T.; Schaeffer, J.; Koopmans, M.; Cotten, M.; Le Guyader, F.S. Characterization of Norovirus and Other Human Enteric Viruses in Sewage and Stool Samples Through Next-Generation Sequencing. Food Environ. Virol. 2019, 11, 400-409. [CrossRef] [PubMed]

47. Fernandez-Cassi, X.; Timoneda, N.; Martínez-Puchol, S.; Rusiñol, M.; Rodriguez-Manzano, J.; Figuerola, N.; Bofill-Mas, S.; Abril, J.F.; Girones, R. Metagenomics for the study of viruses in urban sewage as a tool for public health surveillance. Sci. Total Environ. 2018, 618, 870-880. [CrossRef] [PubMed]

48. Martínez-Puchol, S.; Rusiñol, M.; Fernández-Cassi, X.; Timoneda, N.; Itarte, M.; Andrés, C.; Antón, A.; Abril, J.F.; Girones, R.; Bofill-Mas, S. Characterisation of the sewage virome: Comparison of NGS tools and occurrence of significant pathogens. Sci. Total Environ. 2020, 713, 136604. [CrossRef] [PubMed]

49. Oshiki, M.; Miura, T.; Kazama, S.; Segawa, T.; Ishii, S.; Hatamoto, M.; Yamaguchi, T.; Kubota, K.; Iguchi, A.; Tagawa, T.; et al. Microfluidic PCR Amplification and MiSeq Amplicon Sequencing Techniques for High-Throughput Detection and Genotyping of Human Pathogenic RNA Viruses in Human Feces, Sewage, and Oysters. Front. Microbiol. 2018, 9, 830. [CrossRef] [PubMed]

50. Johnson, J.A.; Parra, G.I.; Levenson, E.A.; Green, K.Y. A large outbreak of acute gastroenteritis in Shippensburg, Pennsylvania, 1972 revisited: Evidence for common source exposure to a recombinant GII.Pg/GII.3 norovirus. Epidemiol. Infect. 2017, 145, 1591-1596. [CrossRef]

51. Chan, M.C.W.; Hu, Y.; Chen, H.; Podkolzin, A.T.; Zaytseva, E.V.; Komano, J.; Sakon, N.; Poovorawan, Y.; Vongpunsawad, S.; Thanusuwannasak, T.; et al. Global spread of norovirus gii.17 kawasaki 308, 2014-2016. Emerg. Infect. Dis. 2017, 23, 1354-1359. [CrossRef]

52. Green, K.Y.; Belliot, G.; Taylor, J.L.; Valdesuso, J.; Lew, J.F.; Kapikian, A.Z.; Lin, F.C. A Predominant Role for Norwalk-like Viruses as Agents of Epidemic Gastroenteritis in Maryland Nursing Homes for the Elderly. J. Infect. Dis. 2002, 185, 133-146. [CrossRef] 
53. Boon, D.; Mahar, J.E.; Abente, E.J.; Kirkwood, C.D.; Purcell, R.H.; Kapikian, A.Z.; Green, K.Y.; Bok, K. Comparative Evolution of GII.3 and GII.4 Norovirus over a 31-Year Period. J. Virol. 2011, 85, 8656-8666. [CrossRef]

54. Hardy, M.E.; Kramer, S.F.; Treanor, J.J.; Estes, M.K. Human calicivirus genogroup II capsid sequence diversity revealed by analyses of the prototype Snow Mountain agent. Arch. Virol. 1997, 142, 1469-1479. [CrossRef]

55. Santiso-Bellón, C.; Monzó, C.; Fuentes-Trillo, A.; Vila-Vicent, S.; da Silva Ribeiro de Andrade, J.; Gozalbo-Rovira, R.; Buesa, J.; Chaves, F.J.; Rodríguez-Díaz, J. Nearly Complete Genome Sequences of Human Norovirus Belonging to Several Genotypes from Valencia, Spain. Microbiol. Resour. Announc. 2019, 8 , e00641-19. [CrossRef]

56. Ao, Y.; Cong, X.; Jin, M.; Sun, X.; Wei, X.; Wang, J.; Zhang, Q.; Song, J.; Yu, J.; Cui, J.; et al. Genetic Analysis of Re-Emerging GII.P16-GII.2 Noroviruses in 2016-2017 in China. J. Infect. Dis. 2018, 218, 133-143. [CrossRef] [PubMed]

57. Medici, M.C.; Tummolo, F.; Martella, V.; De Conto, F.; Arcangeletti, M.C.; Pinardi, F.; Ferraglia, F.; Chezzi, C.; Calderaro, A. Emergence of novel recombinant GII.P16-GII.2 and GII. P16-GII.4 Sydney 2012 norovirus strains in Italy, winter 2016/2017. New Microbiol. 2018, 41, 71-72.

58. Niendorf, S.; Jacobsen, S.; Faber, M.; Eis-Hübinger, A.M.; Hofmann, J.; Zimmermann, O.; Höhne, M.; Bock, C.T. Steep rise in norovirus cases and emergence of a new recombinant strain GII.P16-GII.2, Germany, winter 2016. Eurosurveillance 2017.

59. Thongprachum, A.; Okitsu, S.; Khamrin, P.; Maneekarn, N.; Hayakawa, S.; Ushijima, H. Emergence of norovirus GII.2 and its novel recombination during the gastroenteritis outbreak in Japanese children in mid-2016. Infect. Genet. Evol. 2017, 51, 86-88. [CrossRef] [PubMed]

60. World Health Organization. Rotavirus vaccines WHO position paper - January 2013. Wkly. Epidemiol. Rec. 2013, 88, 49-64.

61. Kirkwood, C.D. Genetic and Antigenic Diversity of Human Rotaviruses: Potential Impact on Vaccination Programs. J. Infect. Dis. 2010, 202 (Suppl.: S43-8). [CrossRef]

62. Iturriza-Gómara, M.; Dallman, T.; Bányai, K.; Böttiger, B.; Buesa, J.; Dietrich, S.; Fiore, L.; Johansen, K.; Koopmans, M.; KORSUN, N.; et al. Rotavirus genotypes co-circulating in Europe between 2006 and 2009 as determined by EuroRotaNet, a pan-European collaborative strain surveillance network. Epidemiol. Infect. 2011, 139, 895-909. [CrossRef]

63. Estes, M.K.; Kapikian, A.Z. Rotaviruses. In Fields' Virology; Knipe, D.M., Lippincott, H.P., Eds.; Williams \& Wilkins: Philadelphia, PA, USA, 2007; pp. 1918-1974. ISBN 0781760607.

64. Bányai, K.; László, B.; Duque, J.; Steele, A.D.; Nelson, E.A.S.; Gentsch, J.R.; Parashar, U.D. Systematic review of regional and temporal trends in global rotavirus strain diversity in the pre rotavirus vaccine era: Insights for understanding the impact of rotavirus vaccination programs. Vaccine 2012, 30, 122-130. [CrossRef]

65. Delogu, R.; Ianiro, G.; Camilloni, B.; Fiore, L.; Ruggeri, F.M. Unexpected spreading of G12P[8] rotavirus strains among young children in a small area of central Italy. J. Med. Virol. 2015, 87, 1292-1302. [CrossRef]

66. Matthijnssens, J.; Heylen, E.; Zeller, M.; Rahman, M.; Lemey, P.; Van Ranst, M. Phylodynamic analyses of rotavirus genotypes G9 and G12 underscore their potential for swift global spread. Mol. Biol. Evol. 2010, 27, 2431-2436. [CrossRef]

67. Mijatovic-Rustempasic, S.; Teel, E.N.; Kerin, T.K.; Hull, J.J.; Roy, S.; Weinberg, G.A.; Payne, D.C.; Parashar, U.D.; Gentsch, J.R.; Bowen, M.D. Genetic analysis of G12P[8] rotaviruses detected in the largest U.S. G12 genotype outbreak on record. Infect. Genet. Evol. 2014, 21, 214-219. [CrossRef]

68. Pérez-Ortín, R.; Vila-Vicent, S.; Carmona-Vicente, N.; Santiso-Bellón, C.; Rodríguez-Díaz, J.; Buesa, J. Histo-Blood Group Antigens in Children with Symptomatic Rotavirus Infection. Viruses 2019, 11, 339. [CrossRef] [PubMed]

(C) 2020 by the authors. Licensee MDPI, Basel, Switzerland. This article is an open access article distributed under the terms and conditions of the Creative Commons Attribution (CC BY) license (http://creativecommons.org/licenses/by/4.0/). 